University of Zurich

Department of Economics

Working Paper Series

ISSN 1664-7041 (print)

ISSN 1664-705X (online)

Working Paper No. 134

\title{
Do Markets Erode Social Responsibility?
}

Björn Bartling, Roberto A. Weber and Lan Yao

Revised version, August 2014 


\section{Do Markets Erode Social Responsibility?}

\author{
Björn Bartling \\ University of Zurich
}

\author{
Roberto A. Weber \\ University of Zurich
}

\author{
Lan Yao \\ Shanghai University of \\ Finance and Economics
}

August 27, 2014*

Abstract: This paper studies socially responsible behavior in markets. We develop a laboratory product market in which low-cost production creates a negative externality for third parties, but where alternative production with higher costs mitigates the externality. Our first study, conducted in Switzerland, reveals a persistent preference among many consumers and firms for avoiding negative social impact in the market, reflected both in the composition of product types and in a price premium for socially responsible products. Socially responsible behavior is generally robust to varying market settings, such as increased seller competition and limited consumer information, and it responds to costs and prices in a manner consistent with a model in which positive social impact is a utility-enhancing feature of a consumer product. In a second study, we investigate whether market social responsibility varies across societies by comparing market behavior in Switzerland and China. While subjects in Switzerland and China do not differ in their degree of social concern in non-market contexts, we find that low-cost production that creates negative externalities is significantly more prevalent in markets in China. Across both studies, consumers in markets exhibit less social concern than subjects in a comparable individual choice context, though the difference is much smaller in Switzerland.

Keywords: Social responsibility, markets, externalities, competition, cultural differences JEL classifications: C92, D03, D62, M14

\footnotetext{
${ }^{*}$ We thank Friedrich Breyer, Alexander Cappelen, Armin Falk, Ernst Fehr, George Loewenstein, Charles Noussair, Ted O'Donoghue, Arno Riedl, Klaus Schmidt, Nora Szech, Bertil Tungodden, Jean-Robert Tyran, and participants of seminars and conferences in Amsterdam, Beijing, Berlin, Bergen, Bologna, Cologne, Cornell, Honolulu, Maastricht, Munich, New York, Paris, Tilburg, Vienna, Yale, and Zurich for valuable comments. Contact: Bartling and Weber: Department of Economics, Blümlisalpstrasse 10, CH-8006 Zurich, bjoern.bartling@econ.uzh.ch, Tel.: +41 44634 3722; roberto.weber@econ.uzh.ch, Tel.: +41 44634 3688. Yao: School of Economics, 111 Wuchuan Rd, CN-Shanghai 200433, yao.lan@mail.shufe.edu.cn, Tel.: +86 2165902198.
} 


\section{Introduction}

Adam Smith's metaphor of the "invisible hand" illustrates the idea that decentralized interaction of independent actors, through market exchange, leads to efficient allocation of societal resources. In fact, there exists widespread evidence that markets often fulfill this function. However, unregulated market exchange is also often blamed as a source of social ills. For example, citing accounts of environmental damage, animal cruelty, unsafe working conditions and persistent inequality, many scholars have raised the question of whether the inherent nature of market exchange has a perverting influence on people's motivations to exhibit concern for the social impact of their actions (Bowles, 1998; Sandel, 2012; Falk and Szech, 2013; Besley 2013).

Indeed, returning to the efficacy of the invisible hand, an important underlying condition is the absence of negative externalities. When the social costs of market activity are not borne by the trading parties in the market - as in many of the examples above - then markets can systematically underappreciate such impacts, absent some other channel through which they are incorporated. Hence, a standard response to the problem of external effects is to call for an active role for government in regulating or taxing activities that impose externalities, as when markets for products with negative environmental impact, such as $\mathrm{CO}_{2}$ emissions, give rise to regulatory action intended to mitigate the negative consequences of unregulated market activity.

However, an alternative remedy occurs if market participants voluntarily show concern for the social impacts of their actions, thereby resulting in an internalization of external costs. On one hand, firms may voluntarily incur additional production costs to mitigate harm for communities where production occurs or to limit negative environmental impacts. Such concern is potentially reflected, for example, in Apple CEO Tim Cook's statement to shareholders that the firm does "a lot of things for reasons besides profit motive. We want to leave the world better than we found it" (Politi, 2014) - though the extent to which such acts reflect true concern for social impact, rather than for firm reputation and long-term profits, is unclear. On the other hand, consumers may be willing to pay higher prices for products that mitigate potential harm. Indeed, several studies document a willingness by individuals to pay more for such products (Roe, et al., 2001; Johnston, et al. 2001; Louriero, et al., 2001; De Pelsmacker, et al., 2005), though these

estimates are typically obtained by eliciting hypothetical choice or willingness-to-pay measures or by comparing purchasing behavior over distinct market products that may differ in dimensions beyond social impact, such as actual or perceived quality. 
Thus, while the notion of individual and corporate "social responsibility"-a willingness to sacrifice profits or wealth in pursuit of broader social interest-has recently come into focus as a means to prevent efficiency losses due to external effects (Bénabou \& Tirole, 2010), ${ }^{1}$ the extent to which this presents an actual remedy for negative impacts of market activity remains to be better understood. The presence of product labels such as "carbon free," "fair trade" and "cruelty free" in consumer product markets - often associated with higher production costs for firms and prices for consumers - suggests a potential influence of concerns for social impact on market activity. But, in real product markets it is difficult to isolate social responsibility from other possible motives underlying production and consumption of such products.

The possibility that market participants voluntarily internalize the external impacts of their actions is also consistent with evidence from research on non-market decision making, which regularly documents a willingness to consider the impact of one's actions on others (Hoffman, et al., 1994; Andreoni \& Miller, 2002; Fisman, et al., 2007; Cappelen, et al., 2007). Concern for others' welfare, widespread in individual choice contexts, may exist as well with respect to externalities in market settings. However, there is also considerable evidence, which we review below, indicating that repeated exchange in competitive markets crowds out or erodes concerns with fairness and equality, at least between the directly interacting trading parties in the market (Smith, 1962; Roth, et al., 1991; Franciosi, et al., 1995). The question of whether market exchange and competition similarly eliminate concern with the welfare of externality-bearing third parties, who are uninvolved as buyers or sellers in a market, remains an open question.

To address this important issue, we report two laboratory experiments that study the extent to which socially responsible behavior by firms and consumers in markets can mitigate the fundamental problem of negative external effects. Our novel experimental paradigm models a competitive product market, in which sellers decide on a price and on which type of product they want to offer for sale - either one that produces a large negative externality for a third party or one that does not, with the latter involving higher production costs. Thus, importantly, our experiments include a production technology that allows market participants to avoid the external harm caused by exchange, as long as they are willing to incur the corresponding costs. In our markets, following firms' supply decisions, consumers observe the set of offered products

\footnotetext{
${ }^{1}$ This notion is, however, far from new to economics. For example, Arrow (1970) called "attention to a less visible form of social action: norms of social behavior, including ethical and moral codes" and suggested "as one possible interpretation that they are reactions of society to compensate for market failures" (p. 22).
} 
and prices and then choose which products to buy, or whether to buy a product at all. We allow repetition, in order to obtain a sense of what kind of outcomes arise with experience in the market. The standard equilibrium prediction for these markets is that only the cheaper good, which produces the externality, is traded.

In contrast to this standard equilibrium prediction, a baseline market condition from our first experiment - conducted in Switzerland - finds that markets converge rapidly to a stable outcome in which a significant proportion (roughly 45 percent) of products traded cost more to produce, but yield no externality. The prices for such goods are regularly higher than prices for the externality-producing products, though to a lesser extent than the full additional production cost. Thus, in our markets, both sellers and buyers share, on average, some of the burden for preventing the negative externality. Both manifestations of social responsibility are stable over time. We interpret these findings as evidence that preferences over considerations such as social impact, fairness and morality can persist in competitive market exchange.

A broad goal guiding our research is to use our laboratory paradigm to understand how varying factors affect the prevalence of socially responsible market behavior. This is especially important, as real markets sometimes seem to fail to internalize externalities, as with widespread instances of pollution, while in other cases they appear to reflect greater concern for social impacts. The extent to which market participants internalize social impacts thus varies across markets, and maybe societies, and may be influenced by factors such as market characteristics, production technologies and culture. Therefore, our experiments study the robustness of market social responsibility, starting from the high level we observe in the baseline condition with subjects in Switzerland.

First, we study the effect of increased competition between sellers, by adding supramarginal firms to the market, which should theoretically have no effect. However, increased competition might overwhelm concerns with fairness (Roth, et al., 1991) and, more broadly, is often considered a potentially corrupting influence in economic and market behavior (Shleifer, 2004; Cai \& Liu, 2009; Brandts, et al., 2009). In our market, increased competition drives down overall prices, thus yielding greater relative surplus for consumers at the expense of firms. But, there is no detrimental effect of increased competition on the degree of concern exhibited toward externality-bearing parties outside of the market. In fact, the market share of products that yield no externality increases slightly with increased firm competition, as does the price premium for 
the socially responsible product, meaning that consumers pay a higher fraction of the cost of avoiding the externality. Thus, instead of decreasing the expression of social responsibility, increased market competition in this case has, if anything, the opposite effect.

Second, we consider the possibility that consumers may have limited information about the externality produced by available products, but have the ability to learn about such product characteristics. This reflects the fact that many consumers do not know which firms' products are, for example, environmentally or socially harmful, but that such information is often available if a consumer chooses to acquire it. In a setting where consumers are initially uninformed about the types of the offered products, we study both a case in which the information is free and one in which acquiring it involves the consumer incurring a small cost. In both cases, we find that the need for consumers to actively acquire product information regarding social impact has only a small effect-though slightly larger when acquiring information is costly - on the expression of social responsibility in the market.

Third, we study the effect of an alternative production technology under which the cost of externality-free production is considerably higher. In our baseline market condition, this cost equals 20 percent of the surplus created for firms and consumers through exchange. We compare this with a condition in which firms and consumers must forgo 80 percent of the surplus in order to avoid imposing the externality. In this case, the market share of the socially responsible product decreases significantly, by about half, though this lower market share nevertheless remains stable throughout the experiment. This finding indicates that market participants respond to economic factors in deciding whether to act socially responsibly. It also indicates that consumer adoption of socially responsible products - such as renewable energy - may increase with decreasing production costs, or cost subsidies, and provides a basis for understanding why the share of socially responsible trade is higher in some markets than others.

To better understand the nature of preferences for social responsibility, we estimate simple choice models of consumer and firm behavior from our experimental data. For consumers, we estimate a conditional logit choice model (McFadden, 1974) in which we allow utility to be determined both by a consumer's own material profit and by the social impact of a product purchase or choice. This analysis reveals that choices made by consumers in all conditions of our experiment demonstrate a positive concern for both sources of utility, and that this concern is fairly stable across all market conditions. Thus, the social impact of products in 
all of our market conditions can be modeled as a utility-enhancing product attribute that consumers compare to products' relative prices. We also study firms' product supply decisions, and find that firms, on average, respond sensibly to the expected relative profitability of the two types of products, but that their behavior also exhibits a persistent concern among some firms for producing socially responsible products.

Hence, the experimental conditions above generally reveal strong and stable norms of socially responsible behavior in markets conducted in Switzerland. However, it is also important to identify the robustness of such norms to other populations, particularly across societies with varying cultural values, market practices and historical trajectories in economic development. To this end, we report a second study, in which we compare socially responsible market behavior in the subject pool in Switzerland from our first study and in a comparable subject pool in China. Concerns about social impact, such as environmental damage, are ubiquitous in discussions of China's rapidly growing economy and, relatedly, there is debate regarding whether market activity in China reflects less concern for ethics and responsibility than in advanced Western economies (Ip, 2009). Indeed, survey evidence suggests that notions of what constitutes "fair" behavior in markets may differ between Chinese and Western responders, with Chinese responses often judging deceitful and harmful business conduct less harshly (Ahmed, et al., 2003; Lee, et al., 2009; Gao, 2009; Wong, et al., 2010). However, to our knowledge, no empirical data exists that directly tests whether the behavior of Chinese market participants exhibits less concern for social responsibility. To provide such a test, our second study implements a replication of our baseline market in Zurich and in Shanghai. In Switzerland, we replicate the results of our first study: markets converge to a significant share (48 percent) of the more expensive product that yields no externality. In China, however, the market share of the socially responsible product is much lower, at 16 percent. Hence, a direct comparison of the degree of social responsibility exhibited by market participants reveals much less concern in Chinese markets than in Swiss markets.

Moreover, we also implemented an experimental non-market condition, in which individuals in China and Switzerland made identical allocation choices, impacting themselves and two other participants, absent any market context. Consistent with prior research that reveals no systematic directional difference when comparing pro-social behaviors in non-market contexts for Chinese and Western participants (Hemesath \& Pomponio, 1998; Buchan, et al., 
2006; Chuah, et al. 2007; Bohnet, et al., 2008), we find the Chinese to be no less concerned with social impact than participants in Switzerland. These findings suggest that norms of socially responsible market behavior are weaker in China than in Switzerland, even though the general propensity to consider social impacts of one's behavior outside of markets does not differ between the two societies.

Finally, to address the debate regarding whether markets "corrupt" concern for social impact, we also included conditions in both studies that allow us to directly compare the strength of the social concern exhibited by individual participants in our market environment with social concern expressed in a comparable individual, dictator-like, choice context. Our design holds constant most features of the choice contexts across the market and non-market settings, thus allowing us to cleanly compare the impact of a market context on the preferences of individuals facing consequentially identical choice sets. More precisely, we take the choices faced by consumers in our baseline market conditions-across two samples in Switzerland and one in China - and present exactly the same choices, without the market context but with identical monetary consequences for the decision maker and for two other participants (reflecting, implicitly, the roles of sellers and externality-bearing third parties from the market condition), to a new group of participants. We find that in all three comparisons - one from each study in Switzerland and one from Study 2 in China - the frequency of choices mitigating the negative social impact on third parties in this individual, non-market context is higher than in the market context, though the difference is considerably smaller in Switzerland than in China, and is only robustly statistically significant in China. These latter observations are qualitatively in line with recent arguments that markets yield less socially responsible outcomes than comparable individual non-market behavior (e.g., Falk \& Szech, 2013), though the modest differences we observe in Switzerland highlight that social concern may be more robust to market contexts in some populations than in others.

Hence, viewing all our results together, we provide a mixed response to the titular question of our article - do markets erode social responsibility? In particular, in Switzerland we find socially responsible behavior that is widespread across varying market settings and not far below that in non-market contexts. But, our second study, comparing Switzerland and China, reveals that socially responsible market behavior may be very different-and, in some cases, much lower-in different societies. 
The remainder of the paper is structured as follows. In the next section, we review related literature. Sections 3 through 5 present our first study, conducted in Switzerland. Section 3 describes the experimental design. Section 4 presents the results of our market conditions with regard to market shares and prices for the two types of products, while Section 5 presents analyses of individual firm and consumer behavior. Section 6 contains the design and results of our second study, comparing socially responsible behavior in market and non-market contexts between Switzerland and China. Section 7 compares the behavior of consumers in markets to individual allocation choices in highly comparable non-market contexts, using data from both studies. Section 8 concludes and provides a broader interpretation of our results.

\section{Relation to Previous Literature}

An extensive literature shows that experimental markets generally converge toward equilibrium predictions in which considerations such as fairness have minimal impact, even when one side of the market (firms or consumers) captures all of the surplus (Smith, 1962; Plott \& Smith, 1978; Smith \& Williams, 1982; Roth, et al., 1991; Holt, 1995; Franciosi, et al., 1995) and when product purchases create negative externalities for other market participants (Plott, 1983). While this data is often interpreted as evidence that social considerations are minimally important in markets, a key distinction between this and our work is that the kind of social impact we study deals not with fairness or inequality among directly interacting market participants - such as firms and consumers - but, rather, with concern for individuals entirely uninvolved with the exchange process in the market that determines the externality. This is often the case, for example, in situations where production and exchange yield widespread negative social impacts, such as environmental pollution or persistent inequality, or harm to those unable to exert agency, as in the case of labor coercion or animal testing. Our experiment creates a simplified version of such settings and, in contrast with the above literature, we find that concerns for the social impact on such individuals can be persistently manifested in market behavior and outcomes.

Our results also relate to a prominent argument that market exchange crowds out moral values (e.g., Sandel, 2012). Much of the evidence supporting this argument, however, is indirect and does not study the behavior of individuals interacting through markets. For example, experimental findings reveal that framing a non-market interaction with market terminology reduces the apparent importance of moral considerations - such as equality and social welfare- 
among interacting participants (Hoffman, et al., 1994; Ross \& Ward, 1996; Cappelen, et al., 2013). Similarly, the act of assigning monetary value to "good" behaviors, through prices, can crowd out intrinsic motivations for such acts (Frey, et al., 1996; Gneezy \& Rustichini, 2000; Mellström \& Johannesson, 2008). In psychological research, priming people to think of money, in contrast with similar non-monetary primes, leads to more individualistic and less pro-social behavior (Vohs, et al., 2006; see also, Kube, et al., 2012). Thus, while there is considerable indirect evidence that suggests a perverting effect of market exchange, there is little direct evidence on whether moral considerations are truly eroded by market interaction. ${ }^{2}$

One recent study, by Falk and Szech (2013), does study the behavior of participants interacting in bilateral and multi-lateral double-auction markets in a context where, like in our studies, market exchange can produce negative social impact on non-participants in the marketspecifically, the loss of life of a mouse. They find that repeated market interaction generally yields less socially responsible behavior than one-shot non-market decisions, measured by the proportion of individuals willing to accept 10 Euro for the death of a mouse. However, comparing only the extent to which outcomes that produce negative social impacts are generated by market and non-market contexts, the results of Falk and Szech show a limited negative impact of markets. ${ }^{3}$ Moreover, Falk and Szech's comparison of market and non-market decision making changes several aspects of the choice context simultaneously. For example, the non-market treatment involves a one-shot decision, without feedback, that directly leads to social outcomes, while the market context involves repeated decisions, with feedback on others' decisions, in which parties jointly determine outcomes and responsibility is therefore diffused. Any of these features, which are not uniquely market versus non-market differences, may be responsible for a change in behavior. In addition, while the extreme nature of the potential externality (the death of a mouse) is a fascinating feature of Falk and Szech's design, studying morality in markets with varying and possibly less extreme characteristics is important for understanding many nonlaboratory contexts, where tradeoffs are not between money and death, but between different

\footnotetext{
${ }^{2}$ A distinct argument is that the properties of markets may not eliminate moral considerations from the preferences of market participants, but may make them indistinguishable from other motivations under certain conditions governing exchange (Sobel, 2010; Dufwenberg, et al., 2011). A related argument is that "repugnance" to certain kinds of market transactions should be accounted for in the use and design of markets for exchange (Roth, 2007).

${ }^{3}$ In Falk and Szech's individual (non-market) condition, 45.9 percent of subjects accept a 10 Euro payment that kills a mouse, while in a bilateral market, 47.7 percent of possible trades that cause a mouse's death occur (see also, Breyer and Weimann (2014) for further discussion of Falk and Szech's data). Both of these proportions are similar to the frequencies of social harm that we observe across many market conditions in our experiments.
} 
distributions of resources or wealth. In this regard, our design employs a more standard economic methodology by comparing monetary profits for market participants with monetary harm for those affected by a negative externality. This design, more easily suited for future replication and study, also allows easier evaluations in terms of efficiency and welfare. ${ }^{4}$

Finally, and perhaps most importantly, Falk and Szech's markets have only one production technology, which necessarily requires the imposition of a negative externality if exchange occurs. However, many real-world markets are characterized by a multiplicity of production technologies, some of which create fewer negative externalities than others. Indeed, a valuable aspect of markets is that, where a preference to employ a technology that limits external harm exists, market incentives and competition can encourage its adoption. Thus, unlike in the study by Falk and Szech, where market exchange is incompatible, by construction, with acting socially responsibly, our design allows social responsibility to be manifested in market exchange - as long as trading parties are willing to bear the necessary costs. Thus, an important contribution of our study is to highlight the valuable role markets can play in generating socially responsible alternatives to harmful products - provided a feasible technology for doing so.

Our findings also relate to research suggesting that markets and social or moral considerations are compatible. For example, this perspective arises from evidence that exposure of developing societies to market interaction facilitates the adoption of pro-social norms, e.g., of fairness and cooperation (Henrich, et al., 2001; Henrich, et al., 2010; Bowles 2011). Our study shows, directly, that behavior consistent with such norms can persist as a feature of market exchange. ${ }^{5}$ In this sense, our findings also have some similarity to studies demonstrating that efficiency-enhancing reciprocity between buyers and sellers-as when, for example, contractual incompleteness makes trust and trustworthiness necessary for efficient exchange-persists in many kinds of markets (Fehr, et al., 1993; Fehr \& Falk, 1999). While the nature of these results is very distinct from our work, in which contracts between buyers and sellers are complete, we establish the similar finding that social considerations can persist in competitive markets.

\footnotetext{
${ }^{4}$ Moreover, while the double-auction markets used by Falk and Szech are a workhorse of experimental economics, they are often more similar to real-world contexts better described as "bargaining" than to product or labor markets. Smith (1962) contrasted double-auction markets with a posted offer market "to simulate approximately an ordinary retail market. In such markets [...] sellers typically take the initiative in advertising their offer prices, with buyers electing to buy or not to buy rather than taking part in a haggling and bargaining process" (p. 124). Our experiment aims to model such product markets, where discussions of social responsibility are often focused.

${ }^{5}$ Evidence for the importance of fairness norms in markets is also provided by Kahneman, et al. (1986), who show, for example, that people judge as unfair price increases by firms that are not justified by cost increases.
} 
Finally, our second experiment relates to other work that measures differences in preferences and behavior between Chinese and Western individuals in non-market contexts (Buchan, et al., 2006; Chuah, et al. 2007; Bohnet, et al., 2008; Herrmann, et al., 2008). ${ }^{6}$ This work shows that the Chinese tend to be, in general, no less pro-social than Western individualsif anything, they may be slightly more pro-social. However, closest to our work are studies that document, using survey evidence, differing perceptions between Chinese and Western respondents regarding what constitutes ethical or socially responsible behavior in markets (Ahmed, et al., 2003; Lee, et al., 2009; Wong, et al., 2010). For example, Gao (2009) reports the results of surveys conducted in China and Switzerland using Kahneman et al.'s (1986) vignettes describing market behaviors and eliciting judgments of the fairness or unfairness of the behavior. In most domains in which a majority of Swiss respondents (as well as Canadian respondents in Kahneman et al.'s original study) rate behaviors as unfair, Chinese respondents judge the behaviors less harshly. ${ }^{7}$ Our study provides an empirical complement, by testing whether such survey-based perceptions are reflected in the behavior of participants in competitive markets.

More broadly, our second study also highlights the importance of cultural differences in understanding how institutions affect outcomes (North, 1981; Guiso, et al., 2006; Greif \& Tabellini, 2010). As Tabellini (2008) notes, the effectiveness of institutions across countries often depends on distinct notions of morality, or "conceptions of what is right or wrong, and of how one ought to behave in specific circumstances" (p. 257). Our data suggests that, when comparing the efficiency of market institutions, cultural differences may play an important role in what kinds of outcomes ultimately arise.

\section{Study 1: Experimental Design}

\subsection{The Market Game}

Our design develops a novel experimental market environment that contains important features of real-world product markets. Firms and consumers can exchange two types of products, one of which imposes a negative externality on a third party. For simplicity, we label the product that

\footnotetext{
${ }^{6}$ A related prior paper (Kachelmeier \& Shehata, 1992) compares laboratory behavior in China and the United States, using double-auction markets with highly asymmetric equilibrium profits. The results reveal that markets in both countries converge to equilibrium prices, suggesting that the tendency for markets to eliminate concerns for equality between buyers and sellers, which we reviewed earlier, is present in China as well as in the United States.

${ }^{7}$ For example, for the case in which a landlord exploits a tenant's inability to move in order to raise the rent, 91 percent of Canadian respondents in Kahneman, et al.'s, original study judged the behavior as unfair, 92 percent of Swiss respondents did so, while only 63 percent of Chinese non-students and 80 percent of Chinese students did so.
} 
produces no externality $(\mathrm{e}=0)$, i.e., the socially responsible product, as the "fair" product and the product that generates a negative externality $(\mathrm{e}=1)$ as the "unfair" product.

Both product types are worth 50 to the consumer. The production cost of the unfair product is normalized to zero, thus generating a surplus of 50 to firms and consumers when exchanged. However, exchange of this product, which imposes a negative externality of 60 on a third party, is socially harmful and inefficient, with a net welfare impact of $50-60=-10$. In contrast, the fair product has a production cost of $c \in(0,50)$ that is borne by the firm, but has no impact on the third party. In most of our experimental conditions, $c=10$. In all cases, exchange of the fair product is efficient, as it generates a net surplus of $50-c>0$, which is greater than the net surplus of not trading (0) or of trading the unfair product $(-10)$.

Our Market Baseline condition consists of six firms, five consumers and five third parties. All start with 100 units of wealth. Each firm offers a single product, either e $=0$ or $\mathrm{e}=1$, in a posted-offer market, at a price, $p$, determined by that firm. The cost to the firm of producing a fair product is $c=10$. After all firms select product types and prices, consumers enter the market sequentially (in a randomly determined order), observe the current menu of prices and product types, and either choose a single product or reject all available offers. A firm can sell at most one product. Hence, while the consumer who enters the market first can choose among all six product offers, consumers who enter later only see and choose from the remaining offers. Since there are six firms but only five consumers, even the last consumer entering the market can choose from at least two product offers. There is, however, always at least one firm that cannot sell its product. Firms are informed about the product offers - type and price - of all firms in a period, the order in which offers are accepted by consumers, and thus also the offer(s) that remain unsold. The payoff of each of the five third parties is determined by one of the five possible market exchanges between firms and consumers. Specifically, the purchase of an unfair product by a consumer reduces a randomly selected third party's payoff by 60 units, while either the purchase of a fair product or a consumer's decision not to purchase any product yield no impact on the corresponding third party's payoff. Equations (1) to (3) summarize the payoffs in a period. $^{8}$

\footnotetext{
${ }^{8}$ Note that the production costs (when $e=0$ ) and the externality (when $e=1$ ) arise only if a product is sold, which can be interpreted as a "production on demand" technology. We chose this design feature to create a situation in which exchange between buyers and sellers creates the externality.
} 


$$
\begin{aligned}
\Pi^{\text {firm }} & = \begin{cases}100+p-(1-\mathrm{e}) \cdot \mathrm{c} & \text { if he sells his product at price } p \\
100 & \text { otherwise }\end{cases} \\
\Pi^{\text {consumer }} & = \begin{cases}100+50-p & \text { if she buys a product at price } p \\
100 & \text { otherwise }\end{cases} \\
\Pi^{\text {thrid pary }} & = \begin{cases}100-60 \cdot e & \text { if matched with an exchanged product } \\
100 & \text { otherwise }\end{cases}
\end{aligned}
$$

Subjects play 24 rounds of the market game in fixed groups (16-person markets) and roles. We eliminate the possibility of cross-period reputation by not showing subjects the ID numbers of other market participants and by randomly ordering the display of product offers in each period. One round is randomly chosen for payment at the end of the experiment. Each third party is randomly matched to the purchasing decision realized by a particular consumer.

We introduce an explicit market context in the instructions. Players A are described as "sellers" and Players B as "buyers" and they are told they can "trade" different "types of products" at the offered "prices." Player C is neutrally described as "Player C," and the two types of products are called "product without impact on player C" (in case of $e=0$ ) and "product with loss for player C" (in case of $e=1$ ). An English translation of the original German instructions for the Market Baseline condition is included in Appendix C.

\subsection{Varying Market and Technological Characteristics}

To study the robustness of socially responsible market behavior, Study 1 implements additional market variants, each of which changes one characteristic of the market. Specifically, we vary $(i)$ the degree of competition between firms in the market, (ii) the information that consumers have about the types of available products, and (iii) the cost of becoming informed about the characteristics of products. Moreover, we also implement a variation in the production technology by (iv) increasing the production cost of the fair product.

First, in a High Firm Competition condition, we increase the number of firms from six to eight. There are thus always at least three firms in this condition-rather than one in the Market Baseline - that are unable to sell their product offers in each period. Apart from this difference in the number of firms, this condition is identical to the Market Baseline. We expect this increased competition between firms will lead to prices closer to competitive equilibrium than in the Market Baseline, as posted-offer markets typically yield prices above competitive equilibrium (Plott \& Smith, 1978). Our primary focus, however, is on how this increased competition affects the manifestation of social responsibility, e.g., the market share of the fair product. 
Second, we conduct two Limited Information conditions, in which consumers initially have no information regarding the types of different products. Consumers initially only observe the price of each available product, though they are aware that the products might vary based on their social impact. In both conditions, consumers have the opportunity, in each period, to learn the social impact of all available products after observing the prices. If they decide not to acquire this information, they never become informed about the product types in that period, not even about the impact of any product they might purchase-i.e., consuming a product provides no information about the social impact of its production. The two conditions vary how costly it is for consumers to become informed. In the Limited Information (Free) condition, a consumer can reveal the product types at no monetary cost, simply by clicking a button. Apart from the fact that consumers do not learn the types of products by default when entering the market, this condition is identical to the Market Baseline. However, it allows us to identify whether an alternative, more natural, informational default affects socially responsible behavior and market outcomes. In the Limited Information (Costly) condition a consumer has to pay a small cost of 1 unit if she chooses to reveal the types of the available products before making a purchasing decision in a period. This adds the realistic feature that it is (minimally) costly for consumers to become informed about the social impact of available products.

Finally, in the High Production Cost condition, we increase the production cost of the fair product to $c=40$, in contrast with the production cost of $c=10$ in the Market Baseline. The High Production Cost condition thus implements a technological change from the Market Baseline, in terms of the cost of mitigating the externality, but is otherwise identical.

\subsection{The No Market Condition}

The above experimental conditions all study the prevalence of concern for social impact under varying market and technological conditions. To provide a non-market benchmark against which to compare the degree of such concern, we conducted a No Market condition. This condition mimics standard distributional decision tasks (i.e., dictator games) typically used to measure concerns for fairness and social impact in individual choice experiments.

Our novel design creates a precise parallel between the monetary consequences of the product choices made by consumers in a given round in the Market Baseline and the allocation choices made by decision makers in our No Market condition. To achieve this, we present each decision maker in the No Market condition with the exact sequence of choices faced by a yoked 
consumer in the Market Baseline. That is, for each consumer in the Market Baseline, who faced a sequence of 24 menus of product offers, we have a decision maker in the No Market condition who faces a sequence of 24 identical, in monetary terms, neutrally framed allocation choices.

We implement three-person groups (Players “A," "B," and "C"), in which Players B (corresponding to consumers in our market conditions) choose between different allocations of payoffs among all three players. Players $\mathrm{A}$ and $\mathrm{C}$ are thus inactive in this condition. ${ }^{9}$ The assignment of subjects to roles is fixed for the 24 rounds. As in the Market Baseline, one of the 24 rounds is randomly chosen to determine payoffs at the end of a session.

Our design compares the behavior of individuals - in the roles of "consumers" or as neutrally framed decision makers-between market and non-market settings. Specifically, we aim to study the tradeoffs people make between personal benefits and the welfare of others in two very distinct and important settings: an individual choice context similar to the widely studied dictator game and a context designed to simulate consumer choice in product markets. For this purpose, we employ a design that allows us to identify differences in individuals' preferences between the two contexts, measured by choices among consequentially identical sets of alternatives. By holding the monetary consequences of these choices constant, while also keeping the choice procedures and interface very similar, our design creates a clear basis for this comparison, relative to one in which we change more features of the choice environments. ${ }^{10}$

\subsection{Predictions}

The standard economic assumptions of self-interest and rationality yield the same prediction for all the market conditions: all consumers purchase the unfair product, which is traded at a price of zero. The resulting outcomes are maximally inefficient, since each unit of the unfair good traded results in a net social loss.

\footnotetext{
${ }^{9}$ For example, suppose a consumer in Market Baseline can choose between three different products: $(i)$ one fair product at price, $p=30$, (ii) one fair product at price, $p=25$, and (iii) one unfair product at price, $p=15$. There is also always the option (iv) not to buy a product at all. Then, the corresponding four allocation options for a Player B in the No Market condition are: (i) 120 for Player A $(100+30-10), 120$ for Player B $(100+50-30)$, and 100 for Player C (100 - 0); (ii) 115 for A $(100+25-10), 125$ for B $(100+50-25)$, and 100 for C $(100-0)$; (iii) 115 for $\mathrm{A}(100+15-0), 135$ for B $(100+50-15)$, and 40 for $\mathrm{C}(100-60)$; and (iv) 100 for each player.

${ }^{10}$ For example, an alternative approach might compare our Market Baseline to a non-market condition in which a single subject plays the role of firm and consumer and can choose among all payoff combinations (price and product type) available in our market setting. Such a design, by taking a decision collectively produced by multiple subjects (firms and consumers) and making it the responsibility of a single subject, would essentially test diffusion of responsibility. Extensive evidence documents that diffused responsibility significantly decreases concern for social impact, even in contexts not involving markets (Darley \& Latane, 1968; Dana, et al., 2007; Hamman, et al., 2010).
} 
Our experiment also allows the possibility of socially responsible behavior, reflected in market shares and prices. If concern for social impact is a persistent characteristic of market participants' preferences, and such concern is sufficiently strong, then we expect positive and constant market shares for the fair product. While we do not propose a formal model of social responsibility in this paper, in Appendix A we provide a straightforward application of a standard model of social preferences (Fehr \& Schmidt, 1999) to our setting. The model predicts that consumers and firms sufficiently concerned with fairness and inequality are willing to bear additional costs for socially responsible products that do not harm the third party. The model also predicts a decreased market share for the fair product as the cost of mitigating the externality, $c$, increases, but the predicted market is insensitive to increased firm competition and costless limited information (and also essentially insensitive to very small costs of becoming informed). ${ }^{11}$

\subsection{General Procedures and Information}

All sessions took place at the computer laboratory of the Department of Economics at the University of Zurich. Subjects were mainly students from the University of Zurich and the Swiss Federal Institute of Technology (ETH) in Zurich. Students majoring in economics or psychology were not eligible to participate. Study 1 employed a total of 613 participants in a betweensubjects design; that is, each subject participated in only one condition. Table 1 gives an overview of our treatment conditions and the number of observations. We conducted between 6 and 7 independent markets for each market condition, each using between 96 and 112 subjects. We also conducted 3 sessions of the No Market condition, with 105 subjects.

The study was conducted using the software z-Tree (Fischbacher, 2007). Before entering the lab, each subject randomly drew a place card that specified at which computer terminal to sit. The terminal number determined a subject's role as either firm (participant A), consumer (participant B), or third party (participant C). Subjects received written instructions, including comprehension questions that had to be answered correctly before a session could begin. A summary of the instructions was read aloud by the experimenter to ensure common information about payoff functions, choice options, informational conditions, etc., in each of the treatments.

\footnotetext{
${ }^{11}$ However, existing research on social concern in non-market environments shows that many people exploit default informational states to act self-interestedly (Dana, et al., 2007). While inconsistent with most social preference models, such behavior raises the possibility that consumers with limited information will similarly exploit a state of default ignorance about potential negative impacts to purchase low-price products.
} 
Sessions lasted about 1.5 hours. Payoffs from the experiment, denominated in "points," were converted into money at the rate of 10 points to $\mathrm{CHF} 2.50$ (CHF $1 \approx \$ 1$ at the time of the experiment) at the end of a session. On average, subjects earned about CHF 42.0, which includes a show-up fee of CHF 15.

\section{Study 1: Market Shares and Prices}

In discussing the results of Study 1, we proceed as follows. In this section, we first present the results of our Market Baseline condition, to identify the extent to which concern for social impact is reflected in market outcomes, i.e., market shares and relative prices. Then, we study how varying market and technological conditions-increased firm competition, limited consumer information, and increased production costs-influence social responsibility. In Section 5, we shift our attention to the individual behavior of consumers and firms.

We defer a comparison of the Market Baseline and No Market conditions to Section 7 , after presenting the design and results of Study 2 in Section 6. This is because Study 2 also includes identical market and non-market conditions, and we thus present a more thorough analysis using the combined data.

\subsection{Market Baseline}

In 99 percent of cases (831 of 840 consumer choices), consumers purchased a product. Therefore, our analysis will primarily focus on the realized purchases by consumers; unless otherwise noted, we ignore cases in which a consumer made no product purchase.

The solid line in Figure 1 displays the proportion of fair products purchased by consumers across time in the Market Baseline. This statistic identifies how often the externality on third parties was mitigated and, therefore, corresponds to the efficiency of the market. To smooth random variation across periods, we report data aggregated in three-period blocks. The figure reveals a large and stable share of fair products in the Market Baseline. This share is 50 percent in the first three periods, then decreases slightly, but remains between 42 and 46 percent in all remaining three-period blocks. The overall market share of fair products in the Market Baseline is 44.3 percent. $^{12}$ Thus, as measured by product purchases, we observe a persistent

\footnotetext{
${ }^{12}$ When a consumer's choice set included at least one product of each type, the frequency of fair product purchases is slightly higher (48.1 percent). We also compare purchases based on whether consumers were randomly selected to choose earlier (when there were more product options available) or later in a period. When consumers observed all 6
} 
manifestation of socially responsible behavior in market exchange, with almost half of realized trades revealing an apparent concern for avoiding the imposition of the externality.

Table 2 reports probit regressions, with subject random effects, of consumers' product choices. All models include period as an explanatory variable; the coefficient for this variable is never statistically significant. Model 2 introduces an explanatory variable measuring the size of the choice set available to the consumer (recall that consumers acting later saw subsets of the original product offers), which has no effect on the frequency of fair product choices. ${ }^{13}$ Model 3 restricts the data to cases in which a consumer saw both types of products, again finding no time trend. Model 4 reveals that consumers respond sensibly to prices: they are less likely to purchase a fair product as the lowest price at which one is available rises and, conversely, they are more likely to buy a fair product as the lowest price at which an unfair product is available increases.

Consumers' concern for social impact is also reflected in a persistent price difference for the two types of products. The unmarked lines in Figure 2 show the average purchase prices for the fair and unfair products over time in the Market Baseline. Two trends are clear. First, as in other posted-offer market experiments, prices are above the equilibrium prediction, though there is a general slight decreasing trend in prices over time, consistent with a competitive advantage held by buyers that is increasingly manifested over time. Second, there is a persistent price difference for the two types of products. Products that produce no social harm trade at higher prices than socially harmful products throughout the experiment. This price premium increases over time, from 2.7 in the first six periods to 4.8 in the final six periods. This trend is also illustrated by the solid line in Figure 3, which shows the price premium for the fair product-i.e., the mean price of the fair product minus the mean price of the unfair product - in the Market Baseline condition. By the end of the experiment, when the price premium is approximately 5, the 10 -unit cost of mitigating the externality is thus borne equally by sellers and buyers. The observation that the average price premium is below the additional cost of producing the socially responsible product reflects firms' concern for social impact. ${ }^{14}$

product offers, including at least one product of each type, 45.3 percent purchased fair products. When consumers observed only 2 product offers (i.e., a consumer was last to act) the frequency is 42.5 percent. The small differences suggest that consumers did not strategically alter their behavior to influence choice sets of later-acting consumers.

${ }^{13}$ Alternatively, if we construct binary variables for whether a consumer saw 2, 3, 4, 5 or 6 product offers, and use these variables instead, none of the coefficients is statistically significant.

${ }^{14}$ Offering the fair product led to lower expected profits for firms - the average profit for firms offering fair products was 114.2, while it was 119.1 for firms offering unfair products - but a significant proportion of firms' product offers (44.1 percent) were nevertheless fair. The proportion of fair product offers by firms differs little 
As a complement to the above qualitative description of the price pattern, Table 3 reports regressions that study how prices vary over time and by product type. Model 1 reports estimates using data from the Market Baseline condition and reveals that the general price decrease across time is significant, that the fair product sells at a significantly higher price, and that the gap between the two prices increases over time.

Result 1: Outcomes in the Market Baseline condition reveal a significant and stable concern by consumers and firms for the welfare of the third party, reflected both in market share and in relative prices for the two kinds of products.

\subsection{Increased Firm Competition}

Our second market condition increases the number of firms, from 6 to 8 , thereby increasing competition and likely putting downward pressure on prices. Returning to Figure 1, the dotted line shows that the High Firm Competition condition yields a slightly higher frequency of fair products, relative to the Market Baseline. Specifically, the overall market share of fair products increases from 44 percent to 54 percent. Models 1 and 2 in Table 4 report the results of randomeffects probit regressions of the type of product purchased, comparing the Market Baseline and High Firm Competition conditions. Model 1 shows there to be no significant difference between the Market Baseline (omitted category) and High Firm Competition conditions, in terms of overall fair product market shares over the course of the experiment. Model 2 additionally tests for differences in condition-specific time trends, again revealing no significant treatment effects. Hence, increased firm competition yields a persistent market share for the fair product, which is slightly, but statistically insignificantly, higher than in the Market Baseline.

We also observe the price premium for the fair product that we found in the Market Baseline condition. The marked lines in Figure 2 show prices for the fair and unfair products with High Firm Competition. Reflecting basic economic forces, increased competition clearly has an effect on prices, with lower prices for both types of products than in the Market Baseline. More importantly, for our purposes, the figure also reveals that the price difference for the two types of products persists under High Firm Competition and, if anything, is slightly greater; this is also apparent in the dotted line in Figure 3. With prices converging toward the competitive equilibrium, the price premium of the fair product must eventually reflect the marginal

between the first (43.1 percent) and second (45.2 percent) halves of the experiment. The probability of having an offer accepted was similar for both fair ( 83 percent) and unfair ( 82 percent) product offers. 
production cost for a firm to cover its costs. Importantly, however, many consumers are nevertheless willing to pay the greater price premium for the fair product, as indicated by the high market share for this product. Thus, despite moving market prices closer to the competitive equilibrium, increased firm competition does not erode socially responsible behavior.

Returning to Table 3, in Model 2, we see that the lower prices with High Firm Competition are reflected in the smaller coefficient for the constant term, relative to the Market Baseline. We also observe the persistent price premium for fair products, reflected in the positive and significant coefficient for that variable and for the interaction term with Period, both of which are higher under High Firm Competition than for the Market Baseline condition.

Result 2: Outcomes in the High Firm Competition condition reveal a significant and stable concern for the welfare of the third party, reflected both in market shares and in relative prices for the two kinds of products. Increased firm competition lowers prices relative to the Market Baseline. Socially responsible behavior is slightly, but statistically insignificantly, higher under High Firm Competition than in the Market Baseline.

\subsection{Limited Consumer Information}

We next analyze the case in which consumers initially possess limited information about the types of the different available products in a period, but have the opportunity to acquire such information, either for free or at a small cost. The lines of varying dash length in Figure 1 show that under Limited Information, the overall market share of fair products across all periods decreases to about 40 percent, for both conditions, slightly lower than the 44 percent in the Market Baseline. Looking at the second half of the experiment, where time trends are fairly flat, the fair product market shares are ordered in the manner one would expect-highest in the Market Baseline, lower with Free Limited Information and lowest under Costly Limited Information — but with differences that are not very large in magnitude. Models 3 to 6 in Table 4 provide statistical comparisons of product market shares in the Market Baseline (omitted category) with the two Limited Information conditions. Models 3 and 5 show that there are no significant differences in market shares, for either of the two Limited Information conditions. Models 4 and 6 additionally show that there are also no significant differences in time trends.

A persistent concern for the welfare of the third party is again also reflected in the relative prices of the two product types. ${ }^{15}$ The two varying-length dashed lines in Figure 3 show an increasing price premium for the fair product in both Limited Information conditions.

\footnotetext{
${ }^{15}$ Figure B2 in Appendix B shows prices, separately, for both product types in the Limited Information conditions.
} 
Returning to Table 3, Models 3 and 4 present coefficient estimates for random-effects regressions of price on product type and across time for the two conditions. The price premium for the fair product is statistically significant throughout the experiment and significantly increasing for Free Limited Information, a similar pattern as in the Market Baseline. Under Costly Limited Information, the price premium increases marginally significantly over time, but the overall difference only becomes statistically significant after a few periods. ${ }^{16}$

Result 3: Outcomes in both Limited Information conditions reveal a significant and stable concern for the welfare of the third party, reflected both in market shares and in relative prices for the two kinds of products. Relative to the Market Baseline, the concern for the welfare of the third party, manifested in purchasing behavior, is slightly, but not significantly, reduced when acquiring product information is costly.

In Appendix B, we provide a detailed analysis of consumers' information acquisition and subsequent purchase decisions. Here, we summarize a few important observations. Consumers in the Limited Information (Free) condition acquired product information 73 percent of the time. Consistent with basic economic intuition, information acquisition in the Limited Information (Costly) condition is less frequent (42 percent). These frequencies of information acquisition are fairly stable across time. Moreover, information acquisition appears to be instrumental. Consumers who do not acquire information end up purchasing unfair products 87 percent of the time $;{ }^{17}$ conversely, a large majority of consumers who pay for information purchase fair products. Thus, information use appears generally sensible, with those consumers interested in acting socially responsibly purchasing and using the information and those less concerned with social impact simply remaining uninformed and purchasing the least expensive product.

\subsection{High Production Cost}

Finally, we consider the market with a high production cost for the socially responsible product. Recall that, in all prior conditions, the marginal cost of producing the socially responsible product equals 10 units, or 20 percent of the surplus from exchange. In this alternative condition, the cost increases to 40 , or 80 percent of the surplus.

\footnotetext{
${ }^{16}$ Specifically, statistical rejection of the condition that, Fair Product $+t *$ Period X Fair Product $=0$, based on the estimates in Model 3, reaches a level of significance of $\mathrm{p}=0.05\left(\chi^{2}(1)=3.77\right)$ in period $t=3$.

${ }^{17}$ While consumers who do not acquire information in either condition do not know (and are not informed, ex post) which type of product they are purchasing, they almost always purchase the cheapest product available, which is typically an unfair product. The high level of product type information reflected in offer prices might partly explain the small effect of consumers' limited information on market outcomes.
} 
The dashed line in Figure 1 shows that this increase in the cost of producing the socially responsible product leads to a considerably lower market share: 24 percent across all periods, close to half of that in the Market Baseline. Models 7 and 8 in Table 4 provide statistical comparisons of fair product market shares in the Market Baseline and High Production Cost conditions. Consistent with Figure 1, the latter yields significantly lower frequencies of fair products, with no time trend in either condition. Thus, while previous changes to the marketincreased competition and limited information - had little effect on the fair product market share, making the fair product more costly to produce has a much larger impact. However, it is also noteworthy that the market share of fair products remains constant throughout the experiment, revealing stability in socially responsible behavior similar to that in the Market Baseline. ${ }^{18}$

As is evident in Figure 3, there is again a persistent and increasing price premium for the fair product. Not surprisingly, the price premium is higher with High Production Costs - close to 14 units over the entire experiment - than in other market conditions. ${ }^{19}$ As with our other market conditions, however, the average price premium remains below the full cost of socially responsible production, meaning that firms and consumers share the burden of implementing socially responsible outcomes. ${ }^{20}$

Result 4: Outcomes in the High Production Cost condition reveal a significant and stable concern for the welfare of the third party, reflected both in market shares and in relative prices for the two kinds of products. With High Production Cost, the price premium for the fair product is higher and the market share for the fair product is significantly lower than in the Market Baseline.

\section{Study 1: Individual Consumer and Firm Behavior}

Our analysis thus far has focused on aggregate market outcomes - product shares and prices - as a way of studying socially responsible market behavior. We next shift our attention from

\footnotetext{
${ }^{18}$ The high production cost increases, slightly, the frequency with which consumers opt not to buy a product, from 1 1 percent in the Market Baseline to 4.7 across all periods, and 3.9 percent in the second half of the experiment. A random-effects probit regression of no-purchase choices on High Production Cost condition, period, and the interaction of these two variables reveals no significant difference between the High Production Cost and Market Baseline conditions. The frequency of no-purchase choices is low (3.5 percent or below) in all other conditions. ${ }^{19}$ Figure B3 in Appendix B shows prices over time for both product types in the High Production Cost condition. ${ }^{20}$ The theoretical analysis in Appendix A predicts both the lower market share of fair products in the High Production Cost condition and the smaller relative price premium in this condition. While the premium generally approaches or exceeds the threshold at which costs are divided evenly in our other conditions, it remains well below 20 with higher production costs. The model predicts that the price premium equals 10 for $\mathrm{c}=10$, but for $\mathrm{c}=40$ the predicted premium is 20 . The higher demand for the unfair product when $c=40$ necessitates that some "fair" firms offer the unfair product for supply to meet demand. However, since such firms have to be compensated for imposing the externality by offering the unfair product, the market price of such products increases.
} 
aggregate market outcomes to the individual behavior of consumers and firms. If market outcomes truly reflect socially responsible behavior, then such concern should show up as part of a sensible dimension of the decision making of market participants. Moreover, average preferences for social responsibility should be relatively similar across market environments, even when behavior changes in response to market factors like prices and costs.

We first study the behavior of consumers, asking whether social impact can be characterized as a utility-enhancing product attribute in a simple econometric model of consumer choice, and whether the apparent concern held by consumers for this attribute is similarly strong across different market conditions. We also explore the behavior of individual firms, to determine whether they respond to market conditions in a reasonable manner.

\subsection{Consumer behavior}

We assume that individuals potentially care both about their own material payoff and about the social impact of their product choice. A simple way to capture such preferences is with a linear utility function of the form, $u=\theta x+\gamma y$, where $\theta>0$ represents the weight that consumers place on their own monetary payoff (value of the product purchased minus the price paid), indicated by $x$, and $\gamma$ captures their concern for their social responsibility toward the third party, whose payoff is indicated by $y$. Thus, for example, consumers with $\gamma=0$ care only about buying the product at the lowest price, while consumers for whom $0<\alpha \theta=\gamma$ are willing to sacrifice up to $\alpha$ units of own wealth for a one unit increase in the third party's wealth. ${ }^{21}$

We estimate the weights in the above utility specification, using McFadden's (1974) conditional logit choice model. Specifically, Table 5 reports coefficient estimates for utility functions of the form,

$$
u_{i t j}=\theta x_{i t j}+\gamma y_{i t j}+\left(\sum_{k=1}^{K} \alpha_{j k} z_{i t k}\right)+\epsilon_{i t j}
$$

which describe the utility to a consumer, $i$, in period $t$, from product alternative, $j \in\left\{0,1,2, \cdots, J^{i t}\right\}$, where $J^{i t}$ is the number of product alternatives available. The option not to purchase a product, which is always available, corresponds to $j=0$, and the actual number of

\footnotetext{
${ }^{21}$ For simplicity, we assume that consumers do not care about the firm's wealth. As we note earlier, prior experimental evidence suggests that fairness between market participants is often extinguished in repeated market exchange (Kachelmeier, et al., 1991; Roth, et al., 1991; Francoisi, et al., 1995). Indeed, we confirm this to be the case in our data: if we conduct the estimation in this section and additionally include firm profits, the result is a statistically insignificant coefficient for the firm's profit, but no substantive change to any of the other results.
} 
product offers observed by the consumer is indicated by $2 \leq J^{i t} \leq 6$, except for High Firm Competition, where $4 \leq J^{i t} \leq 8$. The variables, $z_{i t k}$, correspond to $K$ variables that vary between cases (i.e., between subjects and periods), but not across alternatives in a case. Specifically, in our estimated models, $K=3$, corresponding to period, female and (the natural logarithm of) age. Because the labeling of the different product options is irrelevant in our experiment (product choice options were unlabeled and were presented in random order), except for the option not to purchase a product in a period (which was always available and uniquely identifiable), we impose the restriction that $\alpha_{j k}=\alpha_{j^{\prime} k}$, for all $j, j^{\prime} \neq 0$. Finally, $\epsilon_{i t j}$ corresponds to an idiosyncratic extreme-value (logit) random utility error.

Model 1 in Table 5 reports the coefficient estimates for $\theta$ and $\gamma$, for the Market Baseline condition. ${ }^{22}$ Consumers care both about their own monetary payoff $(\theta>0)$ and about the welfare of the third party $(\gamma>0)$. Thus, the apparent social concern that we observe in aggregate market outcomes is also apparent in the purchasing behavior of individual consumers. Moreover, the ratio of the two coefficients can be interpreted as the relative concern that the average consumer places on her own payoff versus the payoff of the third party. In the case of the Market Baseline, this ratio is approximately 11 , suggesting that, on average, consumers are willing to sacrifice one unit of wealth to benefit the third party by 11 units.

The remaining models all introduce condition-specific intercept terms to measure the extent to which concern for social impact differs in each condition, relative to the Market Baseline. Specifically, Models 2 through 5 each use data from the Market Baseline and one additional market condition, and introduce an interaction term between condition and third-party earnings, to measure differential concern for the welfare of the third party. Model 6 includes data from all market conditions and simultaneously estimates all the condition-specific interaction terms. The estimates reveal fairly stable concern for social impact across most market conditions, with interaction coefficient estimates that are typically small, positive (indicating, if anything, increased concern for social impact), and generally statistically insignificant. The lone exception is the Limited Information (Costly) condition. When consumers have limited information about the social impact of their purchases and have to pay for such information, their purchasing

\footnotetext{
${ }^{22}$ The table omits the case-specific intercept terms $\left(\alpha_{j k}\right)$. Selecting not to make a product purchase is generally infrequent. However, the coefficient estimates suggest that consumers tended to make the no-purchase option more frequently later in the experiment and as they reported an older age, though these are not always statistically significant. Omitting these intercept terms from the estimated models does not substantively change the results.
} 
behavior reflects decreased concern for the welfare of the third party. ${ }^{23}$ However, if we estimate the model separately for this condition alone, the coefficients for both Consumer Earnings and Third Party Earnings are positive and highly statistically significant $(\beta=0.575(0.010) ; \gamma=0.024$ (0.005); both $\mathrm{p}<0.001)$. Thus, while apparent concern for social impact appears lower in this condition, it is nevertheless present. The overall pattern of stable preferences is striking, and observable quite clearly in Model 6. The same estimated utility weights characterize behavior across all five market conditions: we fail to reject a test of the restriction that all four interaction terms in Model 6 jointly equal zero $\left(\chi^{2}(4)=6.06, p=0.195\right)$.

Result 5: Consumer's purchasing behavior reflects concern for both the price and the social impact of the product and this concern is fairly stable across all market conditions. Compared to the Market Baseline, social concern among consumers, relative to selfinterest, is lower only in the Limited Information (Costly) condition.

\subsection{Firm behavior}

We also study the decisions of individual firms regarding which type of product to produce. Table 6 reports random-effects probit regression results, using as the dependent variable whether a firm chose to offer a fair (1) or unfair (0) product in a period.

Model 1 reveals no differences between conditions in the tendency of firms to offer fair products, with the exception of the High Production Cost condition, where firms offer fair products significantly less frequently. This concords with the general pattern in Figure 1. Model 2 studies the effect of a variable that identifies whether a firm offered a fair product in the previous period. The positive and statistically significant coefficient suggests a tendency to repeatedly offer the same product type across periods; we document such firm-level heterogeneity more precisely in the next section. In Model 3, the variable Expected Fair Product Profit Premium uses a simple measure of the relative expected profitability of the two product types. Specifically, we calculate, for each period in a market, the average realized profit in the prior period for firms that offered the fair product minus the average realized profit for firms that offered the unfair product, including profits of 100 for firms with unsold product offers. This

\footnotetext{
${ }^{23}$ The estimated model ignores the information-acquisition stage and associated cost, i.e., we implicitly assume such costs are zero, and that consumers know the product characteristics. In principle, one could estimate a model that includes the endogenous information acquisition decision, but this requires assumptions regarding beliefs held by consumers about the characteristics of different products, based on observed prices. Given the ad hoc nature of such assumptions, we limit our analysis to a comparison of product purchases based on the known (to the experimenter) characteristics of products and ignore the (small) utility implications of costly information acquisition.
} 
measure identifies how much more (or less) firms earned by offering the fair product than the unfair one. The positive and significant coefficient for this variable indicates that firms respond to the prior relative profitability of the two kinds of products, becoming more likely to offer a fair product as such products become relatively more profitable.

Finally, Model 4 jointly incorporates all the above variables. The type of product offered by the firm in the prior period and the expected profitability of the fair product retain their statistical significance, and the magnitude of the coefficients remains similar to that in Models 2 and 3. However, the treatment effect for High Production Cost decreases substantially in magnitude and is no longer statistically significant. Thus, while Model 1 indicates a treatment effect of High Production Costs on firm decision making, Model 4 reveals that this is largely accounted for by the impact of the higher production costs on expected firm profits.

Result 6: Firms offer more fair products when such products are more profitable. This difference in expected profitability accounts for differences in the frequencies of fair product offers by firms across market conditions. Firms, on average, show a tendency to repeat prior product type choices.

\subsection{Consumer and Firm Heterogeneity}

The above analyses obscure potentially significant individual differences in concern for social impact. Indeed, individual choice experiments-e.g., using dictator games-usually reveal heterogeneous concerns for fairness (Camerer, 2003; Engel, 2011).

Figure 4 presents histograms showing, separately, how often each consumer purchased or each firm offered a fair product, pooling the individual's decisions across periods. We present here only the data for the Market Baseline, though graphs for all conditions are in Appendix B. The top two panels, A and B, show the individual behavior of buyers and sellers, respectively, over the entire experiment; the bottom two panels, C and D, do so for the second half of the experiment (Periods 13-24). For consumers, we consider only those periods in which the consumer had a choice between at least one fair and one unfair product.

Looking at the entire experiment, in Panels A and B, we see considerable heterogeneity in firm and consumer behavior. For example, while some consumers (6 percent) never purchase a fair product, a larger proportion (14 percent) does so in every period. A similar pattern obtains for firms: a smaller proportion (12 percent) never offers a fair product than those who always do 
so (19 percent). Moreover, while both graphs have mass at the extremes, the majority of subjects lie in between - purchasing or offering both types of products over the course of the experiment.

In the second half of the experiment, in Panels $\mathrm{C}$ and $\mathrm{D}$, there is greater differentiation in both firm and consumer behavior. Among consumers, the proportion that never purchase the fair product increases to 23 percent, while the proportion who always do so is even higher (29 percent). For firms, the proportions are similar: 24 and 26 percent, respectively. Thus, for both consumers and firms, behavior in the second half of the experiment reflects both high degrees of heterogeneity and invariance in individual behavior. Roughly half of firms and consumers either always offer or purchase the fair product or never do so. This finding is similar across all market conditions - behavior of both firms and consumers is always bimodal, but the proportions of the two extremes changes across conditions in a manner consistent with Figure 1 (see Appendix B).

Result 7: Individual consumer and firm behavior in the market reflect heterogeneous concerns for the third party. A large proportion of individual behavior is highly stable across the second half of the experiment.

\section{Study 2: Market and Non-Market Behavior in China and Switzerland}

Our first study shows that many market participants, in Switzerland, take into account the external impacts of their market activity. We next explore possible variation across societies in social responsibility, by conducting a second experiment jointly in Switzerland and China.

\subsection{Design}

The primary focus of our study consists of sessions of the Market Baseline condition, conducted as described in Section 3.1, in Switzerland and China. In these Market China and Market Switzerland conditions, 5 consumers and 6 firms interacted exactly as in Study 1, with their market behavior potentially affecting 5 third parties.

Aside from measuring social concern in markets in Switzerland and China, we also obtain comparable measures of social concern in non-market contexts in both countries. This helps us identify, for example, whether any difference in market socially responsible behavior between the two populations is due to a more general difference in social preferences, or whether the market context has different effects in the two countries. Hence, we also conducted sessions of the No Market condition, as described in Section 3.3, in both Switzerland and China. As 
before, each decision maker in the No Market condition faced the identical 24 choices, in terms of monetary consequences for three people, confronting a buyer in the Market condition. ${ }^{24}$

However, while the No Market condition in a country is directly comparable to the corresponding country's Market condition, the No Market conditions are not directly comparable across countries because the choice sets provided to the two sets of non-market decision makers in the two countries differ. Therefore, we also conducted a "swapped" variant of the No Market condition in which we provided a decision maker in a No Market session conducted in Switzerland with a sequence of 24 choices faced by a paired consumer in the Market China condition. Similarly, we provided subjects in the Swapped No Market China condition with the choices faced by consumers in Switzerland. Hence, these Swapped No Market conditions allow a direct comparison of non-market behavior across the two societies. ${ }^{25}$

At the end of each session, we also administered the Fair Market Ideology scale developed by Jost, et al. (2003). This questionnaire measures whether individuals perceive free markets as a fair system and whether inequality produced by markets is fair. We included this scale to test whether, consistent with prior research, Chinese respondents tend to judge market behavior that produces inequality less harshly than respondents in Switzerland (Gao, 2009).

\subsection{General Procedures and Information}

We conducted the experiment at the University of Zurich and the Shanghai University of Finance and Economics. A total of 616 subjects participated, half in China and half in Switzerland. Table 7 provides the number of subjects who participated in each condition. Aside from 8 Market sessions in China and 8 in Switzerland, we also conducted No Market sessions, using all of the consumer choices from that country's Market sessions. Finally, in each country, we also collected Swapped No Market observations for a representative subsample of 4 markets from the other country and presented the 24 choices faced by the 20 consumers in those markets to participants in Swapped No Market sessions conducted in the other country.

The general procedures were as described in Section 3.6. After conducting sessions in China, which recruited from the broad subject population at the Shanghai University for Finance

\footnotetext{
${ }^{24}$ For example, in the No Market China condition, a subject in the role of decision maker (Player B) made 24 allocation choices identical to those faced by a consumer in the Market China condition.

${ }^{25}$ For example, a decision maker in China (Swapped No Market China condition) and one in Switzerland (No Market Switzerland condition) are provided with the same 24 allocation choices in a non-market context, and these choices are identical to the 24 product choices faced by a market consumer in the Market Switzerland condition.
} 
and Economics, we recruited from a comparable distribution of study majors in Zurich-roughly 50 percent from the fields of finance, economics and business (Study 2 thus uses a slightly different population for the Zurich sessions than Study 1, which omitted students from majors related to economics). To ensure comparability between the two sets of instructions, we employed a back-translation procedure in writing the Mandarin version of the experimental instructions - one person translated the English instructions into Mandarin and another person back into English, to identify and reconcile inconsistencies. The conversion from points into money aims to match the purchasing power of subjects' payoffs: points were converted into money at the rate of 10 points to CNY 2.5 in Shanghai and, as in Study 1, 10 points to CHF 2.50 in Switzerland. On average, subjects in China earned about CNY 40.7, including a show-up fee of CNY 15; subjects in Switzerland earned about CHF 41.3, including a show-up fee of CHF 15.

\subsection{Results}

We first consider responses to the Fair Market Ideology questionnaire (Jost, et al., 2003), to identify whether subjects in China hold different notions of what constitutes fair behavior in markets (Gao, 2009). We construct an aggregate measure by averaging the responses to the 25 scale items, ranging from -5 to 5 . Higher numbers reflect greater agreement with the view that market systems and the outcomes they produce are fair. The average response in China is significantly higher than the average response in Switzerland (respectively, mean (S.E) $=0.714$ $(0.011)$ vs. $\left.-0.102(0.016), \mathrm{t}_{614}=8.70, \mathrm{p}<0.001\right)$. Hence, we find a greater general perception among respondents in China that the outcomes produced by free markets are fair. ${ }^{26}$

Our primary interest is in whether we observe differences in market behavior. The solid lines in Figure 5 present the frequencies of fair product purchases in the Market conditions in Switzerland (no markers) and China (markers). ${ }^{27}$ The frequency of fair products traded in Switzerland, 48.3 percent across the entire experiment, is very similar to that in the Market Baseline from Study 1 (44.3 percent), which provides a direct replication of Result 1, using a new sample of subjects, including different study majors, in Switzerland. However, the

\footnotetext{
${ }^{26} \mathrm{We}$ find a similar pattern in individual item responses. For example, for the statement, "In free market systems, people tend to get the outcomes that they deserve" (completely disagree: -5 , completely agree: +5 ), respondents tend to agree significantly more in China than in Switzerland (1.987 vs. $\left.-1.075, \mathrm{t}_{614}=13.67, \mathrm{p}<0.001\right)$. For the statement, "When a company raises the prices that it charges its customers for its goods, because management has obtained market research which suggests that its customers are willing to pay more, it is ..." (completely unfair: -5 , completely fair: +5$)$, Chinese respondents judged the behavior as more fair $\left(1.292\right.$ vs. $\left.0.633, \mathrm{t}_{614}=3.15, \mathrm{p}<0.01\right)$. ${ }^{27}$ As with Study 1, we omit cases in which no product was traded ( 3 percent in Switzerland, 2 percent in China).
} 
frequency of fair product purchases in China is much lower: 16.3 percent across the experiment. Hence, despite studying identical market environments, we observe significantly less socially responsible behavior in China than in Switzerland. In fact, the frequency of socially responsible market outcomes in China is lower than in any condition from Study 1 (see Figure 1), including the one in which the cost of mitigating the externality was four times as high. ${ }^{28}$

Models 1 and 2 in Table 8 report random-effects probit regressions of fair product purchases across experimental locations and time. Consistent with Figure 5, the likelihood of a fair product exchange is significantly lower in China than in Switzerland, and this difference is stable over time. ${ }^{29} \mathrm{We}$ also used the data to estimate the utility models from Section 5.1, separately, for consumers in Switzerland and China (see Appendix Table B1). Recall that the ratio between the weights placed on own payoffs $(\theta)$ and those of the third party $(\gamma)$ measures the relative concern by consumers, on average, for these two impacts of a choice. For Switzerland, the estimated ratio is 13 , which is close to the estimate of 11 from Study 1. However, for China it is almost twice as high (25).

Importantly, however, even though the manifestation of social responsibility is weaker in China than in Switzerland, we nevertheless observe a persistent market share for the socially responsible product even in the market in China. As Figure 5 and Table 8 show, this proportion is stable over time. Hence, despite it being weaker than in Switzerland, we find evidence of market social responsibility also in China. ${ }^{30}$

The No Market conditions using the swapped choice sets common to both Switzerland and China allow us to directly compare the degrees of social concern in non-market settings in the two countries. This is important for interpreting the difference between the two Market conditions in Figure 5. On the one hand, this difference might simply reflect a general difference in the propensity to consider the welfare of others, in which case we would expect subjects in

\footnotetext{
${ }^{28} \mathrm{We}$ also observe differences in the price dynamics between Switzerland and China. Average prices in Market Switzerland sessions are quite similar to those in Study 1, with average prices for the fair product of 30.1 and for the unfair product of 24.7, and a general decreasing trend over the course of the experiment. In China, we observe a smaller price premium (26.1 vs. 24.9) that decreases over the course of the experiment; in the final third of the experiment there is no difference in price for the two types of products in the markets conducted in China.

${ }^{29}$ As in Study 1, consumers in both countries respond sensibly to prices, purchasing fair products more often as the price of fair products decreases and as the price of unfair products increases. We also tested whether differences in the tendency for consumers to purchase socially responsible products related to individual variation in responses to the Free Market Ideology scale. We find no robust relationship between the survey data and behavior in the market.

${ }^{30}$ This is also reflected in the estimated consumer utility weights, which reveal a significant positive concern for both own payoff and the welfare of the third party (see Table B1).
} 
Switzerland to also exhibit greater social concern in the No Market condition than those in China. However, this is inconsistent with earlier laboratory evidence showing Chinese not to be systematically less pro-social in non-market laboratory decisions (Hemesath \& Pomponio, 1998; Buchan, et al., 2006; Chuah, et al. 2007; Bohnet, et al., 2008). Alternatively, it is possible that the difference in behavior arises because of differences in norms specifically governing behavior in markets, with Chinese individuals exhibiting a greater tolerance for unfair or unethical behavior in markets than respondents in Switzerland, as reflected in responses to the Fair Market ideology scale and in prior research.

Figure 5 presents data from the No Market condition in both countries. To allow comparability between No Market data from Switzerland and China, we include only the choices that were part of the "swapped" versions of the No Market conditions. Hence, the No Market lines are based on the same 40 choice sets, each faced by one subject in Switzerland and one in China. In the non-market context, we find very little difference in behavior between Switzerland and China. Across the entire experiment, both subjects in Switzerland and in China select choices that do not harm the third party 56.7 percent of the time. ${ }^{31}$ Models 3 and 4 in Table 8 report the results of random-effects probit regressions that test for differences in non-market behavior between Switzerland and China - again, using only the directly comparable swapped choice sets. There is no statistically significant difference in either levels of exhibited social concern, nor in time trends. ${ }^{32}$

Result 8: Outcomes in both the Market Switzerland and Market China conditions reveal stable concern for the welfare of the third party. The market share of the fair product is significantly lower in China than in Switzerland. Social concern in the No Market context is very similar between China and Switzerland.

\section{Market versus Non-Market Social Concern}

The design of both studies includes No Market conditions that allow direct comparisons between the choices made by individual consumers in the Market Baseline condition and by a comparable group of subjects in the No Market condition. Recall, from the experimental design of Study 1 in Section 3, that we created the No Market condition by taking the 24 product choice sets facing

\footnotetext{
${ }^{31}$ If we include the default choice that gives 100 to each subject, and count this as a fair choice, the proportions rise to 62.4 percent in Switzerland and 60.4 percent in China. These frequencies do not differ significantly.

32 Appendix Table B1 reports estimated utility weights from the swapped No Market choice data for both countries. We find very similar degrees of concern for the third party in Switzerland and China, with both models yielding ratios of approximately 6 between concern for own payoff $(\theta)$ and concern for the third party $(\gamma)$.
} 
each consumer in the Market Baseline condition, and presenting these exact 24 choices - with identical monetary consequences for a set of three subjects - to another decision maker in the No Market condition. Thus, from a purely monetary point of view, the 24 choice sets faced by a subject in the No Market condition are identical to the 24 choices sets faced by a consumer in the Market Baseline. We did the same for the two market conditions in Study 2, Market Switzerland and Market China. Hence, we have three data sets, two in Switzerland and one in China, with which to make market vs. non-market comparisons of the degree of concern for social impact.

Figure 6 presents the frequencies of fair product purchases and fair non-market choices across all three data sets, as well as the pooled data from Switzerland for Studies 1 and 2. The solid lines indicate fair product purchases in the market conditions and are comparable to the corresponding lines in Figures 1 and 5, except that here we include not purchasing a product in the market and the default egalitarian choice in the non-market conditions - which yield payoffs of 100 for all three participants - as "fair." 33 In every comparison, the Market and No Market lines reflect choices from identical choice sets. The top two panels show a similar finding in the two studies in Switzerland: in both cases, the proportion of fair behavior is higher in the No Market condition than in the Market condition, with differences of 10 percent in Study 1 and 18 percent in Study 2. The bottom-left panel, which pools the data from both studies in Switzerland, shows an aggregate difference of 14 percent. These differences are fairly stable across periods. We observe a similar pattern in China, shown in the bottom-right panel. Here, the difference is larger (25 percent), which is consistent with our observation in Section 5 that there is a greater difference between market and non-market social concern in China than in Switzerland. ${ }^{34}$

Table 9 presents the results of random-effects probit regressions of whether a subject made a fair or unfair choice. The results support the observations from Figure 6. The first two models compare the Market Baseline and No Market from Study 1, the next two do so for

\footnotetext{
${ }^{33}$ In the No Market conditions, this is a natural interpretation of the default choice. Recall that not purchasing a product is rare (1 percent) in the Market Baseline in Study 1, which is also true in Study 2 (3 percent in Market Switzerland and 2 percent in Market China). The corresponding default choice is more frequent in the No Market conditions: 3 percent in Study 1, 8 percent in Switzerland (Study 2) and 11 percent in China.

${ }^{34}$ The difference for China is somewhat constrained by the fact that many choice sets faced by consumers and decision makers in China (54 percent) contain no fair product alternative, other than the default, which is much less frequent in the choice sets from markets in Switzerland (Study 1: 26 percent, Study 2: 24 percent), and is a consequence of firms offering fewer fair products in China. If we compare only cases in which a consumer saw at least one fair product and one unfair product (see Appendix Figure B8), the differences between market and nonmarket fair behavior do not change much for Switzerland (for example, the aggregate difference with the pooled data is 15 percent, which is close to the 14 percent difference in Figure 6), but this difference becomes much larger for China (35 percent).
} 
Market Switzerland and No Market Switzerland from Study 2, while models 5 and 6 pool the data from both studies in Switzerland. Across models 1-6, the constant term is not significantly different from zero, indicating that the frequency of fair choices in markets in Switzerland was close to 50 percent. The coefficients for No Market are always positive, but only statistically significant in some specifications, indicating that, while we consistently observe more fair behavior in the non-market context, the statistical strength of this result is inconsistent. Nevertheless, the pooled sample, where we observe the strongest statistical result, finds at least a marginally significant tendency to act more fairly in the non-market context than in the market.

Models 7 and 8 present a comparison of Market China and No Market China. Here, we observe interesting differences with models 1-6. First, the coefficient for the constant term is negative and statistically significant, indicating a strong tendency toward the unfair product type in the market. However, the coefficient for the No Market variable is positive and similarly large and statistically significant in both specifications. Hence, as we observed in Section 6, the impact of market versus non-market contexts is stronger in China than in Switzerland. ${ }^{35}$

Result 9: Socially responsible behavior is more prevalent in the No Market condition than in the corresponding Market condition across all comparisons. The differences are stronger in magnitude and statistical significance in China than in Switzerland.

\section{Conclusion}

This paper studies whether concerns for social responsibility persist in repeated market interaction. We develop a laboratory product market, in which socially responsible behavior by firms and consumers involves incurring additional production costs to mitigate potential negative externalities imposed on individuals otherwise uninvolved with the market.

The data from Study 1, conducted in Switzerland, show, first, that there is a non-trivial share of socially responsible products supplied and demanded in all our market conditions, and that-importantly - the market share of the fair product is stable over time in all conditions. Second, the socially responsible product, which costs more to produce, sells at a price premium

\footnotetext{
${ }^{35}$ In Appendix Table B2 we again estimate the utility model from Section 5.3, allowing concern for the third party to vary between market and non-market contexts. Consistent with Table 9, this interaction is small and statistically insignificant for the comparison in Switzerland from Study 1, but larger in both size and statistical significance for the Swiss data in Study $2(\mathrm{p}<0.05)$ and for the pooled Swiss data $(\mathrm{p}<0.01)$. For the pooled comparison, the nonmarket context increases the relative weight placed on the third party's payoff by 70 percent (the ratio of importance of own payoff $(\theta)$ relative to that of the third party $(\gamma)$ declines from 13 to 7 ). For China, the differences are much larger in both magnitude and statistical significance - the weight placed on the third party increases by 223 percent (the ratio of own concern versus that for the third party is 28 in the market and 9 in the non-market context).
} 
that persists with market experience. In most cases, this price premium increases over time, suggesting that consumers' willingness to pay for socially responsible products is not eliminated with repeated market interaction. Third, we show that individual-level market behavior is consistent with a preference for positive social impact, though such concerns are heterogeneous.

We also document the robustness of social responsibility in markets to varying market conditions, such as increased seller competition and limited consumer information. ${ }^{36}$ But, we identify one feature of markets for socially responsible products - the technology costs of production - that strongly affects the market share of such products. This suggests a critical role for production subsidies as a mechanism for facilitating the adoption of socially responsible products in markets and improving market efficiency. Importantly, the pronounced reaction of market behavior to higher production costs occurs without substantive changes in the estimated underlying preferences of market participants, suggesting that subjects' preferences for positive social impact are an important mechanism driving behavior in all market conditions. ${ }^{37}$

A critical feature of our markets is that we provide a technology that can mitigate the externality, at a cost to market participants. In this sense, our design allows social responsibility to be consistent with market exchange, rather than entirely orthogonal. ${ }^{38}$ The prevalence of such technologies is widespread in many existing markets. For example, "green," "ethical sourcing" and "cruelty-free" are essentially production methods that typically involve higher costs that must be borne in some combination by firms and consumers. Hence, it is natural to study social responsibility in the presence of such technologies, and to understand their role in facilitating socially responsible market behavior. Indeed, our experiment provides clear evidence of the importance of such technologies, and of their costs, for social responsibility in markets.

Study 2, comparing behavior in Switzerland and China, addresses the possibility that socially responsible market behavior is not solely driven by market characteristics or technology,

\footnotetext{
${ }^{36}$ Further evidence that socially responsible market behavior is robust to alternative market characteristics is provided by Danz, et al. (2012), who show experimentally that consumers with monopsony power in a duopoly market setting are willing to pay more for products produced by firms that pay higher wages to their workers. Their focus is on how such consumer concern is affected by variation in minimum wage policies.

${ }^{37}$ Moreover, the robustness of social responsibility in markets to a default state of limited information-which has been shown to strongly decrease social concern in non-market settings (Dana, et al., 2007) - indicates that, at least in some ways, market social responsibility may be robust to factors that negatively impact non-market pro-social behavior. One possible interpretation is that the market context (in comparison with non-market individual choice contexts) already provides individuals willing to exploit justifications for acting self-interestedly the ability to do so.

${ }^{38}$ For related evidence that the feasibility of pro-social outcomes matters for their realization, in the context of principal-agent relationships, see Charness and Dufwenberg (2011).
} 
but also varies between societies. Our data show that the frequency of fair product purchases in China is significantly lower, roughly a third of the level observed in Switzerland, despite the structure of the experimental markets being identical between the two countries. These results show, more broadly, the importance of cultural differences in understanding how institutions, such as markets, affect outcomes (North, 1981). Indeed, the market share of the fair product in China is lower than in any condition from Study 1, which demonstrates that cultural differences can play as important a role for the efficiency of market outcomes as other key economic factors.

Finally, in both studies, we also employ a novel design that allows us to conduct a direct comparison between the behavior of individuals in market and non-market contexts, holding constant most other important factors about the choices they face. Our non-market condition is a variant of the much-studied dictator game and thus provides a useful benchmark to which we can compare the level of pro-social behavior in our laboratory markets. Across three data sets, we observe a consistent pattern - the frequency of pro-social choices is lower in all three cases, though the differences are much stronger in magnitude and statistical significance in China than in Switzerland. Hence, market behavior does seem to reflect less concern for social impact than comparable individual choice settings, even in choices that are consequentially and procedurally identical (cf. Falk \& Szech, 2013). At the same time, social responsibility in our market settings is no less stable over time than that in non-market settings. Moreover, the modest differences we observe in Switzerland, relative to China, highlight that socially responsible behavior may be more robust to market contexts in some societies than in others.

Broadly, our results draw attention to the important challenge of understanding better the organizational, technological, and cultural conditions under which markets affect pro-social behavior. To this end, an appealing feature of our design is that it easily lends itself to further study. Thus, one of our contributions is what we believe to be a valuable and easily modified experimental paradigm for studying the varying conditions for social responsibility in markets. 


\section{References}

Ahmed, Mohamed M., Kun Young Chung, and John W. Eichenseher. 2003. "Business Students' Perception of Ethics and Moral Judgment: A Cross-Cultural Study.” Journal of Business Ethics, 43: 89-102.

Andreoni, James and John Miller. 2002. "Giving According to GARP: An Experimental Test of the Consistency of Preferences for Altruism." Econometrica, 70(2): 737-753.

Arrow, Kenneth. 1970. "Political and Economic Evaluation of Social Effects and Externalities," in: The Analysis of Public Output, Julius Margolis (ed.), National Bureau of Economic Research; distributed by Columbia University Press.

Bénabou, Roland and Jean Tirole. 2010. "Individual and Corporate Social Responsibility." Economica, 77: 1-19.

Besley, Timothy. 2013. "What's the Good of the Market? An Essay on Michael Sandel's 'What Money Can't Buy'.’ Journal of Economic Literature, 51(2): 478-495

Bohnet, Iris, Fiona Greig, Benedikt Herrmann and Richard Zeckhauser. 2008. "Betrayal Aversion: Evidence from Brazil, China, Oman, Switzerland, Turkey, and the United States." American Economic Review, 98(1): 294-310.

Bowles, Samuel. 1998. "Endogenous Preferences: The cultural consequences of markets and other economic institutions." Journal of Economic Literature, 36:75-111.

Bowles, Samuel. 2011. “Is Liberal Society a Parasite on Tradition?” Philosophy and Public Affairs, 39(1): 46-81.

Brandts, Jordi, Arno Riedl and Franz van Winden. 2009. "Competitive rivalry, social disposition, and subjective well-being: An experiment." Journal of Public Economics, 93: $1158-1167$.

Breyer, Friedrich and Joachim Weimann. 2014. "Of morals, markets and mice: A comment on Falk and Szech.” CESifo Working Paper No. 4745.

Buchan, Nancy R., Eric J. Johnson and Rachel T. A. Croson. 2006. "Let's get personal: An international examination of the influence of communication, culture and social distance on other regarding preferences." Journal of Economic Behavior \& Organization, 60: 373-398.

Cai, Hongbin and Qiao Liu. 2009. “Competition and Corporate Tax Avoidance: Evidence for Chinese Industrial Firms.” Economic Journal, 119: 764-795.

Camerer, Colin F. 2003. Behavioral Game Theory. Princeton University Press.

Cappelen, Alexander W., Astri D. Hole, Erik Ø. Sørensen and Bertil Tungodden. 2007.

"The pluralism of fairness ideals: An experimental approach." American Economic Review, 97(3): 818-827. 
Cappelen, Alexander W., Erik Ø. Sørensen and Bertil Tungodden. 2013. "When do we lie?" Journal of Economic Behavior \& Organization, 93: 258-265.

Charness, Gary, and Martin Dufwenberg. 2011. "Participation." American Economic Review, 101(4): 1211-1237.

Chuah, Swee-Hoon, Robert Hoffmann, Martin Jones, and Geoffrey Williams. 2007. “Do cultures clash? Evidence from cross-national ultimatum game experiments." Journal of Economic Behavior \& Organization, 64: 35-48.

Dana, Jason, Roberto A. Weber, and Jason Xi Kuang. 2007. "Exploiting moral wiggle room: Experiments demonstrating an illusory preference for fairness." Economic Theory, 33(1): $67-80$.

Danz, David, Dirk Engelmann, and Dorothea Kübler. 2012. "Do Legal Standards Affect Ethical Concerns of Consumers? An Experiment on Minimum Wages." University of Mannheim, Department of Economics, Working Paper 12-3.

Darley, John and Bibb Latane. 1968. "Bystander Intervention in Emergencies: Diffusion of Responsibility.” Journal of Personality and Social Psychology, 8(4): 377-383.

De Pelsmacker, Patrick, Liesbeth Driesen, and Glenn Rayp. 2005. "Do Consumers Care about Ethics? Willingness to Pay for Fair Trade Coffee.” Journal of Consumer Affairs, 39(2): 363-385.

Dufwenberg, Martin, Paul Heidhues, Georg Kirchsteiger, Frank Riedel and Joel Sobel. 2011. "Other-Regarding Preferences in General Equilibrium.” Review of Economic Studies, 78: 640-66.

Engel, Christoph. 2011. "Dictator Games: A Meta Study.” Experimental Economics, 14: 583610.

Falk, Armin and Nora Szech. 2013. “Morals and Markets.” Science, 340: 707-711.

Fehr, Ernst and Armin Falk. 1999. "Wage Rigidity in a Competitive Incomplete Contract Market." Journal of Political Economy, 107(1): 106-34.

Fehr, Ernst, Georg Kirchsteiger, and Arno Riedl. 1993. "Does Fairness Prevent Market Clearing? An Experimental Investigation.” Quarterly Journal of Economics, 108: 437-59.

Fehr, Ernst and Klaus M. Schmidt. 1999. “A Theory of Fairness, Competition, and Cooperation." Quarterly Journal of Economics, 114, 817-868.

Fischbacher, Urs. 2007. "z-Tree: Zurich toolbox for ready-made economic experiments." Experimental Economics, 10(2): 171-78.

Fisman, Raymond, Shachar Kariv, and Daniel Markovits. 2007. "Individual Preferences for Giving." American Economic Review, 97(5): 1858-1876. 
Francoisi, Robert, Praveen Kujal, Roland Michelitsch, Vernon Smith and Gang Deng. 1995. "Fairness: Effect on Temporary and Equilibrium Prices in Posted-Offer Markets." Economic Journal, 105: 938-950.

Frey, Bruno S., Felix Oberholzer-Gee, and Reiner Eichenberger. 1996. "The Old Lady Visits Your Backyard: A Tale of Morals and Markets." Journal of Political Economy, 104(6): 1297-1313.

Gao, Yue. 2009. "A study of fairness judgments in China, Switzerland and Canada: Do culture, being a student, and gender matter?” Judgment and Decision Making, 4(3): 214-226.

Gneezy, Uri and Aldo Rustichini. 2000. “A Fine Is a Price.” The Journal of Legal Studies, 29(1): 1-17.

Greif, Avner and Guido Tabellini. 2010. "Cultural and Institutional Bifurcation: China and Europe Compared." American Economic Review, 100(2): 1-10.

Guiso, Luigi, Paola Sapienza and Luigi Zingales. 2006. "Does Culture Affect Economic Outcomes?" Journal of Economic Perspectives, 20(2): 23-49.

Hamman, John, George Loewenstein, and Roberto A .Weber. 2010. "Self-Interest through Delegation: An Additional Rationale for the Principal-Agent Relationship." American Economic Review, 100(4): 1826-46.

Hemesath, Michael and Xun Pomponio. 1998. "Cooperation and Culture: Students from China and the United States in a Prisoner's Dilemma." Cross-Cultural Research, 32(2): 171-184.

Henrich, Joseph, Robert Boyd, Samuel Bowles, Colin Camerer, Ernst Fehr, Herbert Gintis and Richard McElreath. 2001. "In Search of Homo Economicus: Behavioral Experiments in 15 Small-Scale Societies." American Economic Review, 91(3): 73-78.

Henrich, Joseph, Jean Ensminger, Richard McElreath, Abigail Barr, Clark Barrett, Alexander Bolyanatz, Juan Camilo Cardenas, Michael Gurven, Edwins Gwako, Natalie Henrich, Carolyn Lesorogol, Frank Marlowe, David Tracer, John Ziker. 2010. "Markets, Religion, Community Size, and the Evolution of Fairness and Punishment." Science, 327: 1480-1484.

Herrmann, Benedikt, Christian Thöni and Simon Gächter. 2008. “Antisocial Punishment Across Societies." Science, 319: 1362-1367.

Hoffman, Elizabeth, Kevin McCabe, Keith Shachat and Vernon Smith. 1994. "Preferences, Property Rights, and Anonymity in Bargaining Games." Games and Economic Behavior, 7: 346-380.

Holt, Charles. 1995. "Industrial Organization: A Survey of Laboratory Research," in The Handbook of Experimental Economics, John H. Kagel and Alvin E. Roth (eds.). Princeton: Princeton University Press. 
Ip, Po Keung. 2008. "The Challenge of Developing a Business Ethics in China." Journal of Business Ethics, 88: 211-224.

Johnston, Robert J., Cathy R. Wessells, Holger Donath, and Frank Asche. 2001. "Measuring Consumer Preferences for Ecolabeled Seafood: An International Comparison." Journal of Agricultural \& Resource Economics, 26(1): 20-39.

Jost, John T., Sally Blount, Jeffrey Pfeffer, and György Hunyady. 2003. "Fair Market Ideology: Its Cognitive-Motivational Underpinnings." Research in Organizational Behavior, 25: 53-91.

Kachelmeier, Steven J. and Mohamed Shehata. 1992. "Culture and competition." Journal of Economic Behavior \& Organization, 19: 145-168.

Kachelmeier, Steven J., Stephen T. Limberg, and Michael S. Schadewald. 1991. “A Laboratory Market Examination of the Consumer Price Response to Information About Producers' Costs and Profits." Accounting Review, 66: 694-717.

Kahneman, Daniel, Jack L. Knetsch, and Richard H. Thaler. 1986. "Fairness as a constraint on profit seeking: Entitlements in the market." American Economic Review, 76:728-741.

Kube, Sebastian, Michel A. Maréchal, and Clemens Puppe. 2012. "The Currency of Reciprocity: Gift Exchange in the Workplace." American Economic Review, 102(4): 164462.

Lee, Nick, Amanda Beatson, Tony C. Garrett, Ian Lings and Xi Zhang. 2009. "A Study of the Attitudes Towards Unethical Selling Amongst Chinese Salespeople." Journal of Business Ethics, 88: 497-515.

Loureiro, Maria L., Jill J. McCluskey, and Ron C. Mittelhammer. 2001. "Assessing Consumer Preferences for Organic, Eco-labeled, and Regular Apples." Journal of Agricultural \& Resource Economics, 26(2): 404-416.

McFadden, Daniel. 1974. "Conditional Logit Analysis of Qualitative Choice Behavior. "In: P. Zarembka (ed.), Frontiers in Econometrics, 105-142, Academic Press: New York.

Mellström, Carl and Magnus Johannesson. 2008. "Crowding Out in Blood Donations: Was Titmuss Right?” Journal of the European Economic Association, 6(4): 845-863.

North, Douglas. 1981. Structure and Change in Economic History. Norton.

Plott, Charles R. 1983. "Externalities and Corrective Policies in Experimental Markets." Economic Journal, 93: 106-127.

Plott, Charles R. and Vernon L. Smith. 1978. "An Experimental Examination of Two Exchange Institutions." Review of Economic Studies, 45(1): 133-153. 
Politi, Daniel. 2014. “Apple CEO to Global Warming Deniers: We Don’t Want Your Money," (http://www.slate.com/blogs/the_slatest/2014/03/01/apple_ceo_tim_cook_shoots_down_glo bal_warming_deniers_at_shareholders_meeting.html)

Roe, Brian, Mario F. Teisl, Alan Levy, and Matthew Russell. 2001. "US consumers' willingness to pay for green electricity." Energy Policy, 29(11): 917-925.

Ross, Lee and Andrew Ward. 1996. "Naïve Realism in Everyday Life: Implications of Social Conflict and Misunderstanding." In: T. Brown, E. S. Reed and E. Turiel (Eds.), Values and Knowledge (pp. 103-135). Hillsdale, NJ: Erlbaum.

Roth, Alvin E. 2007. "Repugnance as a Constraint on Markets." Journal of Economic Perspectives, 21(3): 37-58.

Roth, Alvin E., Vesna Prasnikar, Masahiro Okuno-Fujiwara and Shmuel Zamir. 1991. "Bargaining and Market Behavior in Jerusalem, Ljubljana, Pittsburgh and Tokyo: An Experimental Study," American Economic Review, 81: 1068-1095.

Sandel, Michael. 2012. What Money Can't Buy. New York: Farrar, Straus and Giroux.

Shleifer, Andrei. 2004. "Does Competition Destroy Ethical Behavior?" American Economic Review Papers and Proceedings, 94(2): 414-418.

Smith, Vernon L. 1962. “An Experimental Study of Competitive Market Behavior.” Journal of Political Economy, 70(2): 111-137.

Smith, Vernon L. and Arlington W. Williams. 1982. "The Effects of Rent Asymmetries in Experimental Auction Markets." Journal of Economic Behavior \& Organization, 3(1): 99116.

Sobel, Joel. 2010. “Do Markets Make People Look Selfish?” Mimeo, University of California, San Diego.

Tabellini, Guido. 2008. "Institutions and Culture." Journal of the European Economic Association, 6(2-3): 255-294.

Vohs, Kathleen D., Nicole L. Meade and Miranda R. Goode. 2006. "The Psychological Consequences of Money." Science, 314: 1156.

Wong, Alan, Fu Long and S. Elankumaran. 2009. "Business Students' Perception of Corporate Social Responsibility: The United States, China, and India." Corporate Social Responsibility and Environmental Management, 17: 299-310. 
Table 1. Session Overview and Number of Observations

\begin{tabular}{lcccc} 
Treatment & Markets & $\begin{array}{c}\text { Firms } \\
\text { (Participant A) }\end{array}$ & $\begin{array}{c}\text { Consumers } \\
\text { (Participant B) }\end{array}$ & $\begin{array}{c}\text { Third Parties } \\
\text { (Participant C) }\end{array}$ \\
\hline Market Baseline & 7 & 42 & 35 & 35 \\
High Firm Competition & 6 & 48 & 30 & 30 \\
Limited Information (Free) & 6 & 36 & 30 & 30 \\
Limited Information (Costly) & 6 & 36 & 30 & 30 \\
High Production Cost & 6 & 36 & 30 & 30 \\
No Market & - & 35 & 35 & 35 \\
\hline
\end{tabular}

Table 2. Random-effects Probit Regressions of Fair Consumer Product Choice in Market Baseline Condition

\begin{tabular}{lcccc} 
& \multicolumn{2}{c}{ All periods } & \multicolumn{2}{c}{$\begin{array}{c}\text { Consumer saw both types } \\
\text { of products }\end{array}$} \\
& $(1)$ & $(2)$ & $(3)$ & $(4)$ \\
\hline Period & -0.007 & -0.007 & -0.013 & 0.014 \\
& $(0.008)$ & $(0.008)$ & $(0.010)$ & $(0.022)$ \\
Number of Product Offers & & 0.054 & & \\
& & $(0.047)$ & & $-0.403^{* * *}$ \\
Lowest price of fair product & & & & $(0.074)$ \\
& & & & $0.385^{* * *}$ \\
Lowest price of unfair product & & & & $(0.063)$ \\
Constant & -0.009 & -0.225 & 0.180 & 2.275 \\
\hline Observations & $(0.211)$ & $(0.252)$ & $(0.248)$ & $(1.826)$ \\
Number of subjects & 831 & 831 & 621 & 621 \\
& 35 & 35 & 35 & 35
\end{tabular}

Omits the nine cases in which a consumer made no product purchase

Robust standard errors in parentheses

$* * * \mathrm{p}<0.01, * * \mathrm{p}<0.05, * \mathrm{p}<0.1$ 
Table 3. Random-effects Regressions of Prices by Product Type

\begin{tabular}{lccccc} 
& $\begin{array}{c}\text { Market } \\
\text { Baseline } \\
(1)\end{array}$ & $\begin{array}{c}\text { High Firm } \\
\text { Competition } \\
(2)\end{array}$ & $\begin{array}{c}\text { Limited Info. } \\
(\text { Free }) \\
(3)\end{array}$ & $\begin{array}{c}\text { Limited Info. } \\
(\text { Costly) } \\
(4)\end{array}$ & $\begin{array}{c}\text { High Prod. } \\
\text { Cost } \\
(5)\end{array}$ \\
\hline \multirow{2}{*}{ Period } & $-0.283^{* * *}$ & $-0.474^{* * *}$ & $-0.574^{* * *}$ & $-0.342^{* * *}$ & $-0.154^{* * *}$ \\
& $(0.037)$ & $(0.066)$ & $(0.051)$ & $(0.055)$ & $(0.048)$ \\
Fair Product & $2.401^{* * *}$ & $3.328^{* * *}$ & $3.121^{* * *}$ & 1.202 & $8.993^{* * *}$ \\
Period X & $(0.651)$ & $(0.846)$ & $(1.153)$ & $(0.934)$ & $(1.448)$ \\
Fair Product & $0.108^{* *}$ & $0.190^{* *}$ & $0.192^{* *}$ & $0.103^{*}$ & $0.115^{*}$ \\
& $(0.050)$ & $(0.079)$ & $(0.078)$ & $(0.062)$ & $(0.066)$ \\
Constant & $26.881^{* * *}$ & $21.812^{* * *}$ & $28.771^{* * *}$ & $30.240^{* * *}$ & $31.974^{* * *}$ \\
& $(0.574)$ & $(0.754)$ & $(0.791)$ & $(0.989)$ & $(0.836)$ \\
\hline Observations & 831 & 711 & 695 & 702 & 686 \\
Num. of subjs. & 35 & 30 & 30 & 30 & 30 \\
& & & & & \\
Robust standard errors in parentheses & & & & & \\
$* * * * \mathrm{p}<0.01, * * \mathrm{p}<0.05,{ }^{*} \mathrm{p}<0.1$ & & & & &
\end{tabular}

Table 4. Random-effects Probit Regressions of Fair Consumer Product Choice in Market Baseline and Alternative Market Conditions

\begin{tabular}{lcccccccc} 
& $\begin{array}{c}\text { Baseline vs. } \\
\text { High Firm } \\
\text { Competition }\end{array}$ & \multicolumn{2}{c}{$\begin{array}{c}\text { Baseline vs. } \\
\text { Limited Info. } \\
\text { (Free) }\end{array}$} & \multicolumn{2}{c}{$\begin{array}{c}\text { Baseline vs. } \\
\text { Limited Info. } \\
\text { (Costly) }\end{array}$} & \multicolumn{2}{c}{$\begin{array}{c}\text { Baseline vs. } \\
\text { High Production } \\
\text { Cost }\end{array}$} \\
\hline \multirow{2}{*}{ Treatment } & $(1)$ & $(2)$ & $(3)$ & $(4)$ & $(5)$ & $(6)$ & $(7)$ & $(8)$ \\
& 0.373 & 0.494 & -0.314 & -0.471 & -0.135 & 0.167 & $-0-896^{* *}$ & $-0867^{* *}$ \\
Period & $(0.359)$ & $(0.333)$ & $(0.374)$ & $(0.378)$ & $(0.307)$ & $(0.308)$ & $(0.387)$ & $(0.401)$ \\
Period X & & -0.007 & & -0.007 & & -0.007 & & -0.007 \\
Treatment & & $(0.008)$ & & $(0.008)$ & & $(0.008)$ & & $(0.008)$ \\
Constant & -0.010 & & 0.013 & & -0.025 & & -0.002 \\
& -0.085 & -0.001 & -0.083 & 0.002 & -0.098 & -0.014 & -0.079 & 0.005 \\
Observations & 1,542 & $(0.209)$ & $(0.232)$ & $(0.211)$ & $(0.225)$ & $(0.204)$ & $(0.234)$ & $(0.213)$ \\
Num. of subjs. & 65 & 1,542 & 1,526 & 1,526 & 1,533 & 1,533 & 1,517 & 1,517 \\
& & 65 & 65 & 65 & 65 & 65 & 65 & 65
\end{tabular}

Omits cases in which consumers made no product purchase Robust standard errors (clustered by subject) in parentheses $* * * \mathrm{p}<0.01,{ }^{* *} \mathrm{p}<0.05,{ }^{*} \mathrm{p}<0.1$ 
Table 5. Estimated Weights for Consumer Utility Model

Baseline Baseline \& Baseline \& Baseline \& Baseline \& All Market Market HF Comp. LI (Free) LI (Costly) High Cost Conditions

(1)

(2)

(3)

$0.372^{* * *}$

$(0.062)$

$0.370^{* * *}$

(4)

(0.054)

$0.033^{* * *}$

$0.032^{* * *}$

(0.006)

(0.007)

$0.395^{* * *}$

(0.044)

$0.439^{* * *}$

(0.054)

$0.034^{* * *}$

(0.006)

(0.006)

(5)

$(\theta)$

0.008

$0.214^{* * *}$

(0.069)

$0.282^{* * *}$

Third Party Earnings

$(\gamma)$

$0.038^{* * *}$

$0.020^{* * *}$

(0.041)

Third Party X

(0.008)

$0.025^{* * *}$

HF Competition

(0.009)

(0.006)

Third Party X

Lim. Info. (Free)

(0.009)

0.005

(0.008)

Third Party X

Lim. Info. (Costly)

$-0.018^{* *}$

0.001

(0.008)

Third Party X

$(0.009)$

$-0.012$

(0.008)

High Prod. Cost

Observations

Cases

840

4,205

840

9,247

1560

7,835
1560

7,821

1560

0.006

(0.009)

0.006

Robust standard errors (clustered by subject) in parentheses

$* * * \mathrm{p}<0.01, * * \mathrm{p}<0.05, * \mathrm{p}<0.1$

The model includes period, gender and $\ln ($ age) as case-specific (intercept) terms (coefficients omitted). 
Table 6. Random-effects Probit Regressions of Firm Product Decisions

\begin{tabular}{|c|c|c|c|c|}
\hline & (1) & (2) & (3) & (4) \\
\hline \multirow{2}{*}{ High Firm Competition } & 0.359 & & & 0.337 \\
\hline & $(0.415)$ & & & $(0.388)$ \\
\hline \multirow{2}{*}{ Limited Information (Free) } & -0.413 & & & -0.346 \\
\hline & $(0.474)$ & & & $(0.448)$ \\
\hline \multirow{2}{*}{ Limited Information (Costly) } & -0.112 & & & -0.067 \\
\hline & $(0.459)$ & & & $(0.434)$ \\
\hline \multirow{2}{*}{ High Production Cost } & $-1.323^{* *}$ & & & -0.565 \\
\hline & $(0.554)$ & & & $(0.522)$ \\
\hline \multirow{2}{*}{ Firm Offered Fair Product Last Period } & & $0.298^{* *}$ & & $0.357^{* * *}$ \\
\hline & & $(0.119)$ & & $(0.126)$ \\
\hline \multirow{2}{*}{ Expected Fair Product Profit Premium } & & & $0.028^{* * *}$ & $0.030^{* * *}$ \\
\hline & & & $(0.004)$ & $(0.004)$ \\
\hline \multirow{2}{*}{ Constant } & -0.123 & -0.504 & -0.209 & -0.250 \\
\hline & $(0.324)$ & $(0.153)$ & $(0.164)$ & $(0.308)$ \\
\hline Observations & 4,752 & 4,554 & 4,396 & 4,396 \\
\hline Number of subjects & 198 & 198 & 198 & 198 \\
\hline
\end{tabular}

Robust standard errors (clustered by subject) in parentheses

Models 2 through 4 exclude the first period; Models 3 and 4 additionally exclude cases in which either a fair or unfair product was not offered in the prior period.

$* * * \mathrm{p}<0.01, * * \mathrm{p}<0.05, * \mathrm{p}<0.1$ 
Table 7. Summary of Data Collected in Study 2

\begin{tabular}{|c|c|c|}
\hline & $\begin{array}{l}\text { Sessions in Switzerland } \\
\text { (University of Zurich) }\end{array}$ & $\begin{array}{l}\text { Sessions in China } \\
\text { (Shanghai University of Finance } \\
\text { and Economics) }\end{array}$ \\
\hline \multirow[t]{4}{*}{ Market } & Market Switzerland $(n=128)$ & \multirow{4}{*}{$\begin{array}{l}\text { Market China }(n=128) \\
40 \text { consumers, } 48 \text { firms, } 40 \text { third parties } \\
8 \text { markets }\end{array}$} \\
\hline & \multirow{2}{*}{$\begin{array}{l}40 \text { consumers, } 48 \text { firms, } 40 \text { third } \\
\text { parties }\end{array}$} & \\
\hline & & \\
\hline & 8 markets & \\
\hline \multirow[t]{3}{*}{ No Market } & No Market Switzerland $(n=120)$ & No Market China $(n=120)$ \\
\hline & 40 decision makers & 40 decision makers \\
\hline & $\begin{array}{l}\text { Choices from all Market } \\
\text { Switzerland markets }\end{array}$ & Choices from all Market China markets \\
\hline \multirow{3}{*}{$\begin{array}{l}\text { Swapped } \\
\text { No Market }\end{array}$} & Swapped No Market China $(n=60)$ & Swapped No Market Switzerland $(n=60)$ \\
\hline & 20 decision makers & 20 decision makers \\
\hline & $\begin{array}{l}\text { Choices from } 50 \% \text { subsample of } \\
\text { Market China markets }\end{array}$ & $\begin{array}{l}\text { Choices from } 50 \% \text { subsample of Market } \\
\text { Switzerland markets }\end{array}$ \\
\hline
\end{tabular}

Table 8. Random-effects Probit Regressions of Fair Choices in Switzerland and China Market China \& Switzerland $\quad$ No Market China \& Switzerland (matched choices)

\begin{tabular}{lcccc}
\hline & $(1)$ & $(2)$ & $(3)$ & $(4)$ \\
\hline \multirow{2}{*}{ China } & $-1.447^{* * *}$ & $-1.529^{* * *}$ & -0.033 & 0.145 \\
& $(0.297)$ & $(0.322)$ & $(0.291)$ & $(0.286)$ \\
Period & & -0.010 & & 0.004 \\
& & $(0.013)$ & & $(0.009)$ \\
Period X China & & 0.006 & & -0.015 \\
& & $(0.017)$ & 0.333 & $(0.013)$ \\
Constant & -0.002 & 0.126 & $(0.206)$ & 0.280 \\
& $(0.219)$ & $(0.246)$ & 1711 & 1711 \\
Observations & 1872 & 1872 & $80.206)$ \\
Number of & 80 & 80 & & 80 \\
subjects & & & &
\end{tabular}

Omits cases in which consumer made no product purchase and the respective choices in the No Market condition Robust standard errors (clustered by subject) in parentheses $* * * \mathrm{p}<0.01, * * \mathrm{p}<0.05,{ }^{*} \mathrm{p}<0.1$ 
Table 9. Random-effects Probit Regressions of Fair Market and Non-Market Choices

\begin{tabular}{lcccccccc} 
& \multicolumn{2}{c}{$\begin{array}{c}\text { Switzerland } \\
\text { (Study 1) }\end{array}$} & \multicolumn{2}{c}{$\begin{array}{c}\text { Switzerland } \\
\text { (Study 2) }\end{array}$} & \multicolumn{2}{c}{$\begin{array}{c}\text { Switzerland } \\
\text { (Combined) }\end{array}$} & \multicolumn{2}{c}{$\begin{array}{c}\text { China } \\
\text { (Study 2) }\end{array}$} \\
\hline & $(1)$ & $(2)$ & $(3)$ & $(4)$ & $(5)$ & $(6)$ & $(7)$ & $(8)$ \\
\hline No Market & 0.345 & 0.317 & $0.801^{* *}$ & 0.584 & $0.586^{* * *}$ & $0.457^{*}$ & $1.030^{* * *}$ & $0.938^{* * *}$ \\
& $(0.324)$ & $(0.305)$ & $(0.314)$ & $(0.358)$ & $(0.226)$ & $(0.238)$ & $(0.279)$ & $(0.290)$ \\
Period & & -0.007 & & -0.012 & & -0.010 & & -0.006 \\
& & $(0.008)$ & & $(0.014)$ & & $(0.008)$ & & $(0.011)$ \\
Period X No & & 0.002 & & 0.018 & & 0.011 & & 0.008 \\
Market & & $(0.012)$ & & $(0.017)$ & & $(0.011)$ & & $(0.015)$ \\
Constant & -0.081 & 0.009 & 0.035 & 0.188 & -0.019 & 0.105 & $-1.339^{* * *}$ & $-1.269^{* * *}$ \\
& $(0.229)$ & $(0.208)$ & $(0.226)$ & $(0.257)$ & $(0.161)$ & $(0.168)$ & $(0.185)$ & $(0.195)$ \\
\hline $\begin{array}{l}\text { Observations } \\
\text { Number of }\end{array}$ & 1680 & 1680 & 1920 & 1920 & 3600 & 3600 & 1920 & 1920 \\
subjects & 70 & 70 & 80 & 80 & 150 & 150 & 80 & 80
\end{tabular}

Includes as "fair" (1) those cases in which consumer made no product purchase and the respective choices in the No Market condition

Robust standard errors (clustered by subject) in parentheses

*** $\mathrm{p}<0.01,{ }^{* *} \mathrm{p}<0.05,{ }^{*} \mathrm{p}<0.1$ 
Figure 1. Fair Product Purchases across Varying Market Conditions

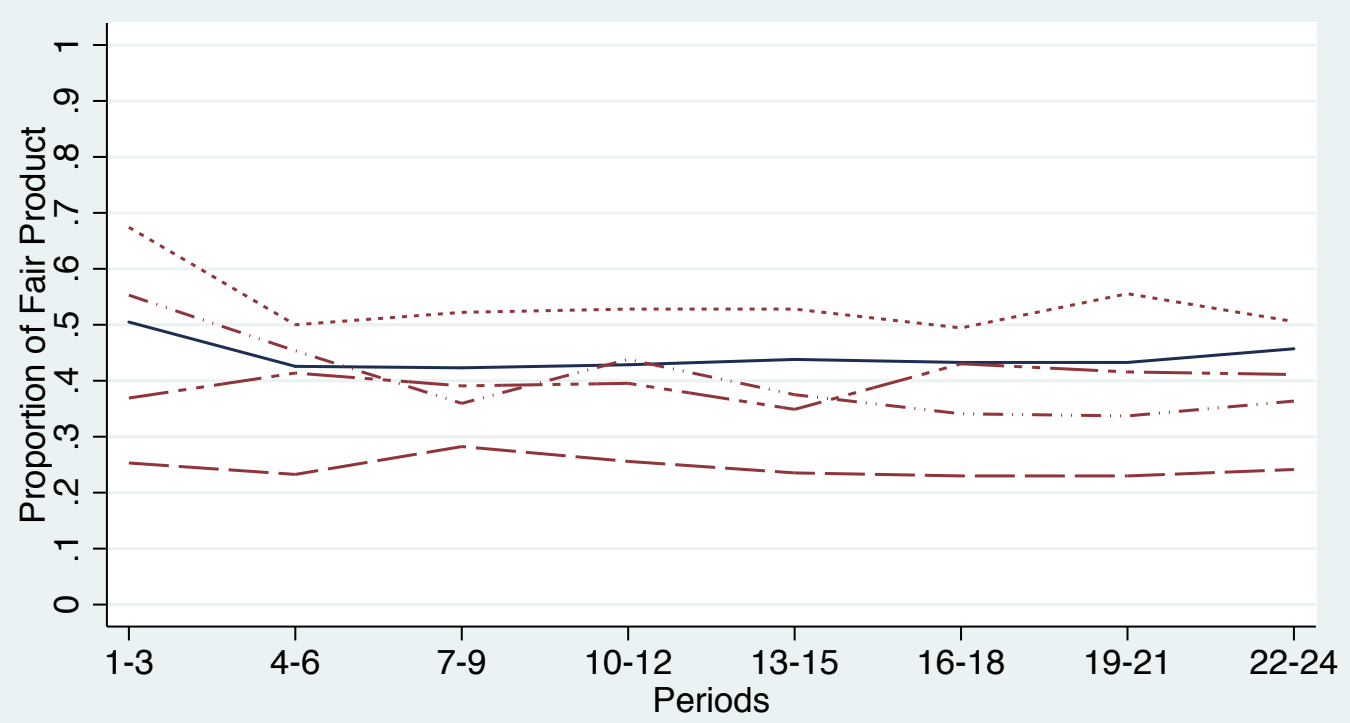

\begin{tabular}{|c|c|}
\hline $\begin{array}{l}\text { Market Baseline } \\
\ldots-\ldots \text { Limited Information (Free) }\end{array}$ & 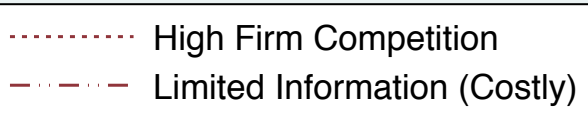 \\
\hline - - - High Production Cost & \\
\hline
\end{tabular}

Data from all completed market transactions

Figure 2. Prices by Product Type in Market Baseline and High Competition Conditions

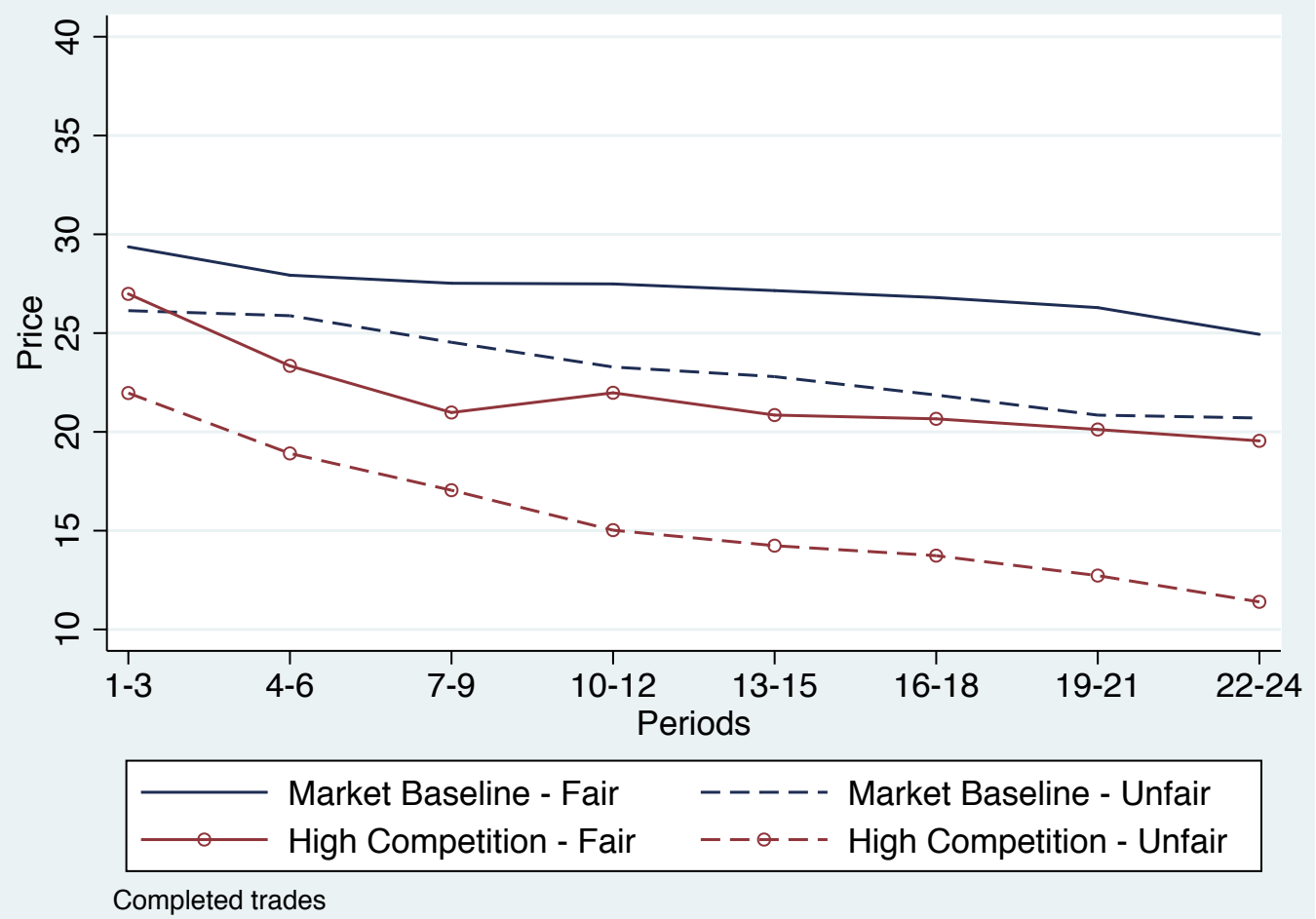


Figure 3. Price Premium for the Fair Product across Varying Market Conditions

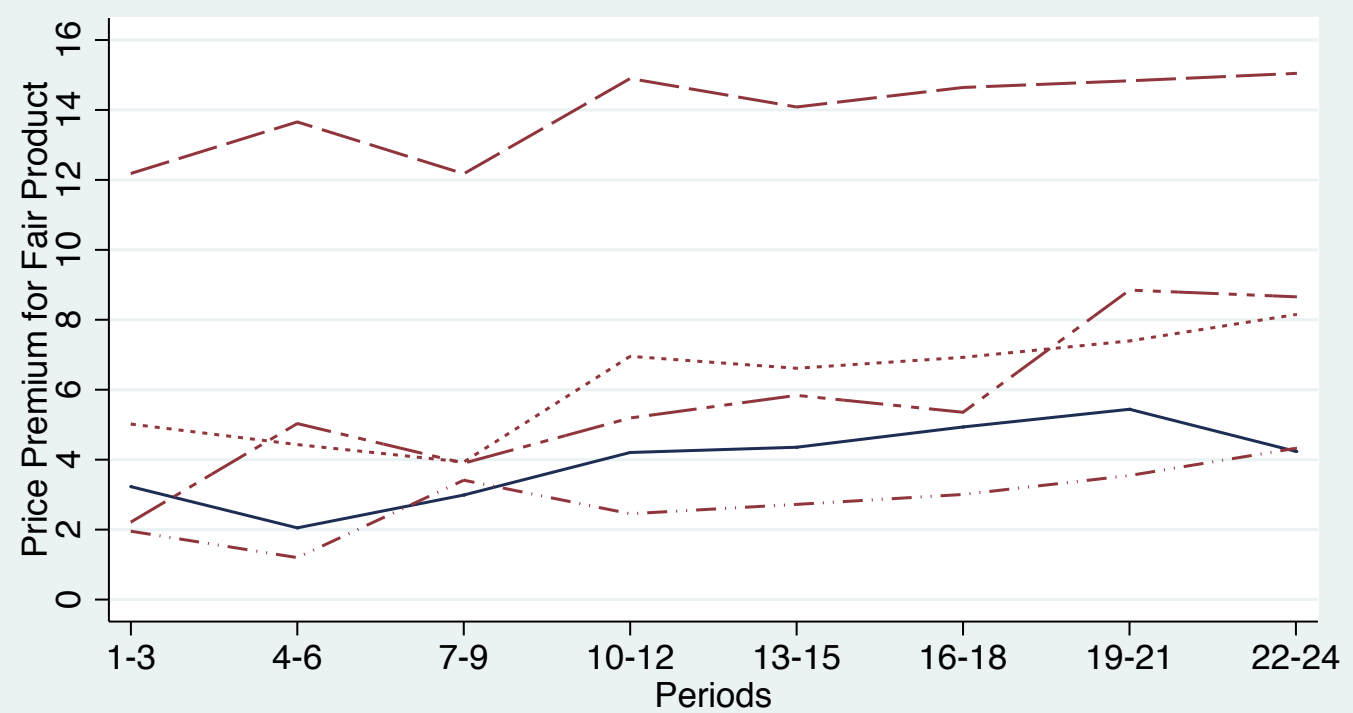

\begin{tabular}{|c|c|}
\hline $\begin{array}{cl}- & \text { Market Baseline } \\
---- \text { Limited Information (Free) } \\
-\_- \text {High Production Cost }\end{array}$ & $\begin{array}{l}\text {.......... High Firm Competition } \\
-\cdots-\text { Limited Information (Costly) }\end{array}$ \\
\hline
\end{tabular}

Data from all completed market transactions 
Figure 4. Distributions of Individual Behavior (Market Baseline)
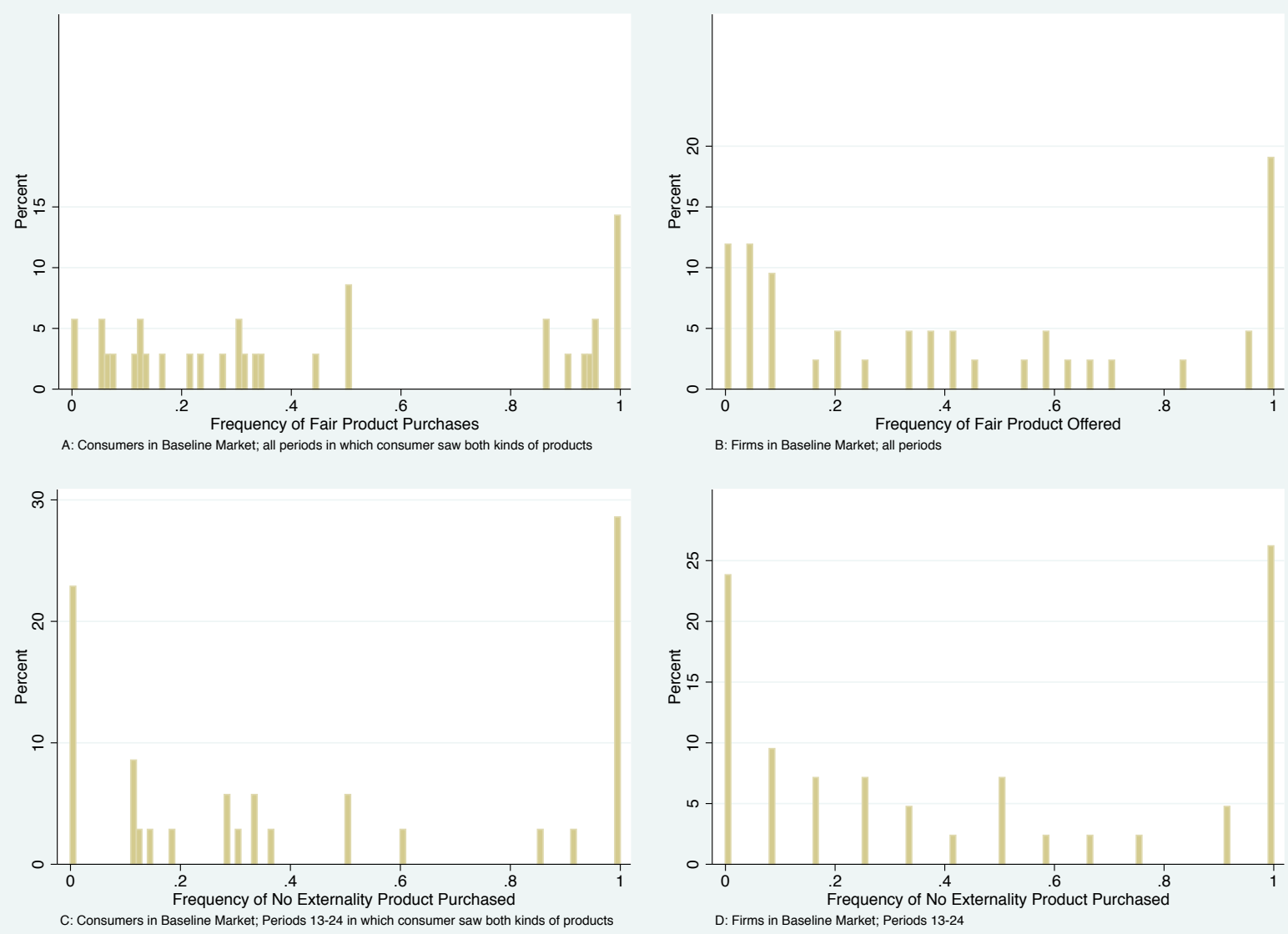
Figure 5. Fair Product Purchases and Choices in China and Switzerland

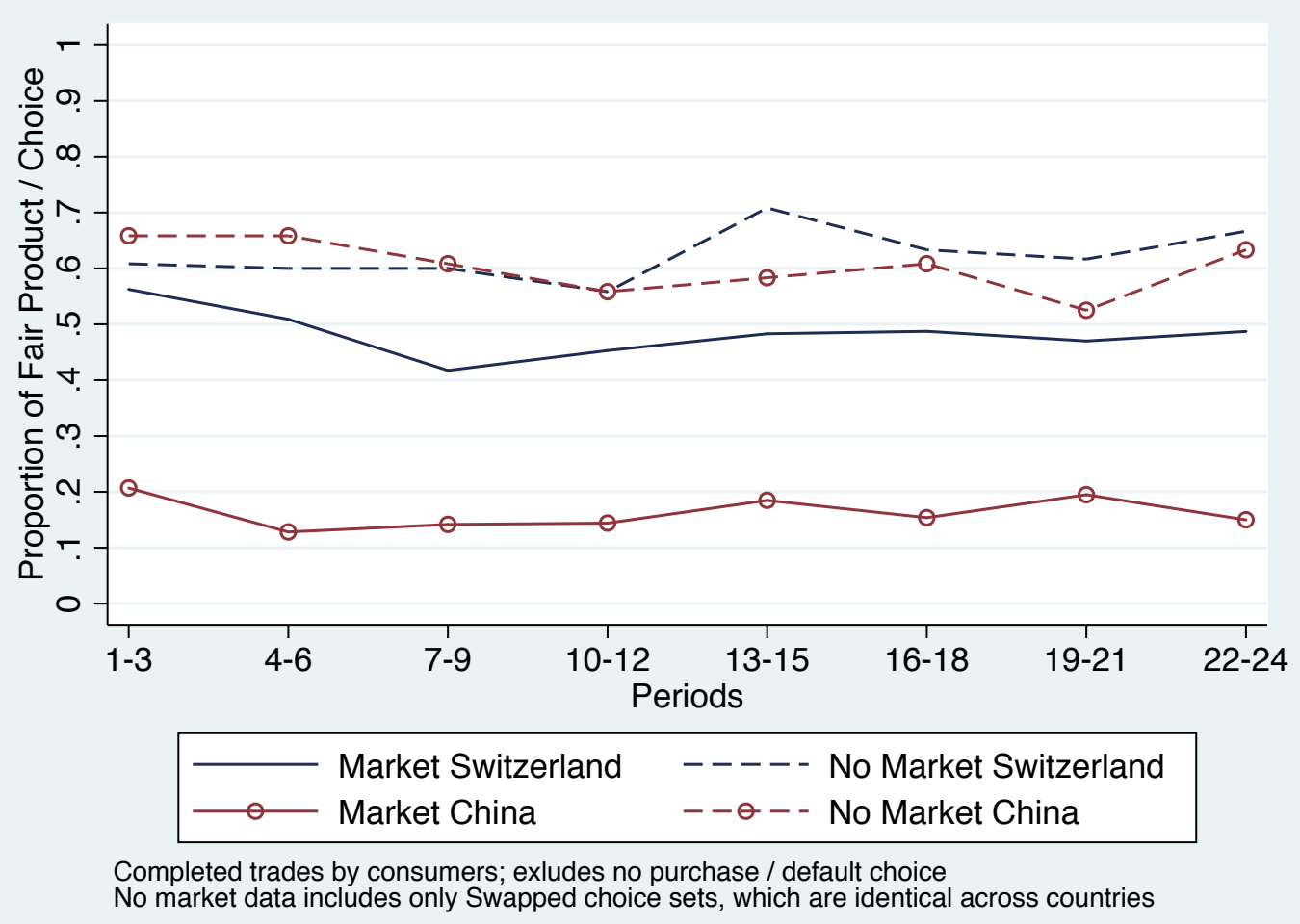

Figure 6. Fair Purchases / Choices in Market and No Market Conditions

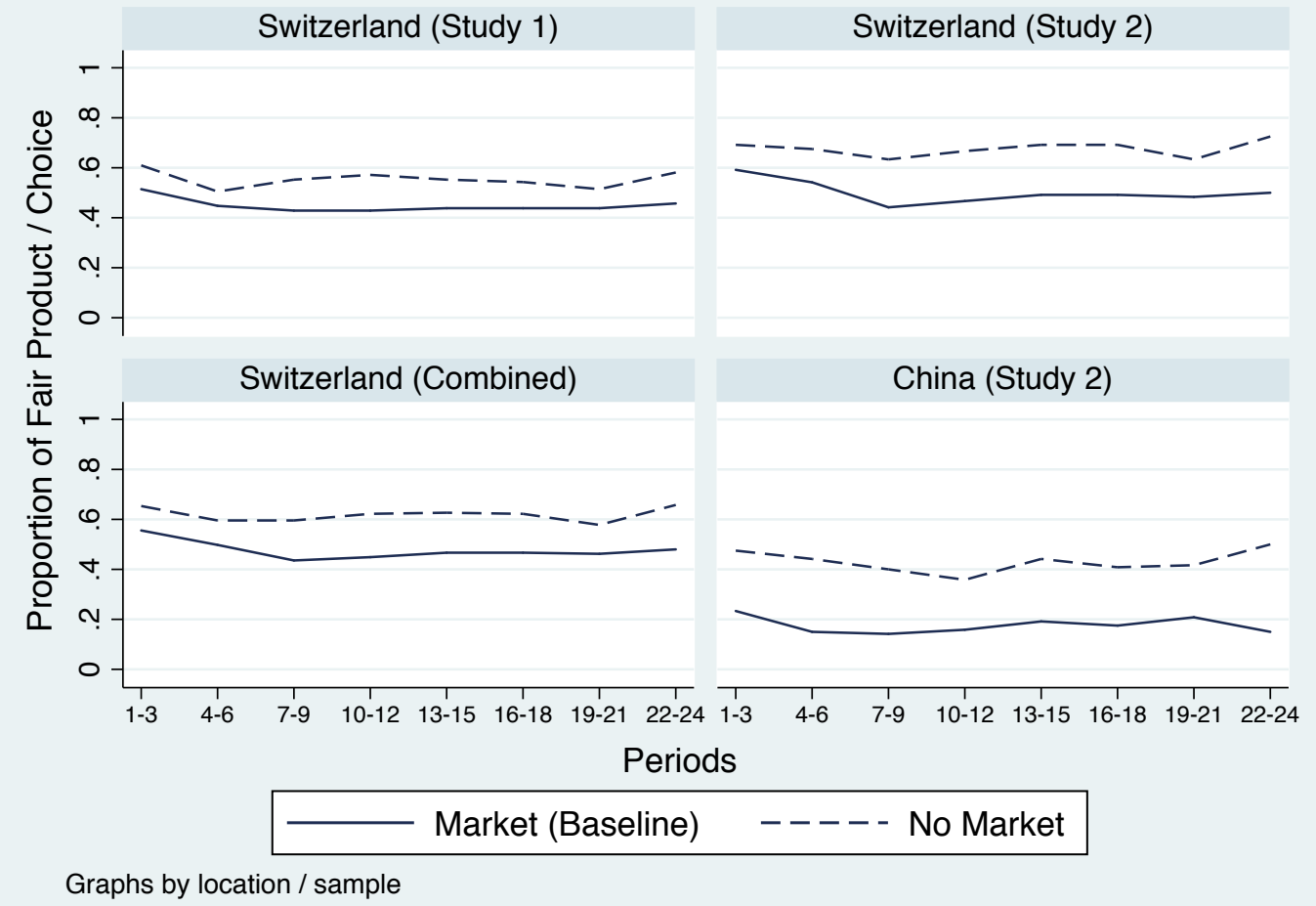




\section{Appendix A: Social Responsibility Modeled as Inequity Aversion}

In this appendix we provide an illustrative example of how a simple model of social preferences can be applied to our experimental markets. Specifically, we analyze firm and consumer decisions using the model of inequity aversion introduced by Fehr and Schmidt (1999). We selected this model because of its simplicity and widespread use in many other applications.

We assume that some consumers and some firms are socially responsible, which we model as inequity aversion with regard to the third party. Since consumers and firms are both free to choose what to trade and at which price, we do not apply the concept of social responsibility to their mutual relationship. We thus maintain the assumption of the pure selfinterest model that consumers and firms do not care about each other's payoffs. As we note in the paper, this model fairly accurately describes convergence to equilibrium predictions in markets that only involve payoff implications for buyers and sellers.

We first derive the price premiums that (i) a consumer is willing to pay for the fair product on top of the price of the unfair product and that (ii) a firm demands for offering the fair product, which is more costly to produce. We show that for sufficiently high degrees of social responsibility (i.e., aversion to advantageous inequality with regard to the third party) trade of the fair product becomes feasible. We then derive the equilibrium predictions for prices and product shares in our baseline and high cost conditions, taking price competition among firms and social preference type heterogeneity into account.

\section{A1. Price premium that a consumer is willing to pay for the fair product}

Consider a socially responsible consumer who experiences a disutility equal to $\beta<1$ times the positive difference between her own payoff and that of the third party, in addition to the utility produced by her own payoff. Denote the consumer's and third party's endowment, respectively, as $m^{c}$ and $m^{t}$, the value of the product as $v$, the size of the externality as $e$, and the prices of the fair and unfair product as $\mathrm{p}^{\text {fair }}$ and $\mathrm{p}^{\text {unfair }}$, respectively. A consumer prefers buying the fair product over buying the unfair product if

$$
\begin{aligned}
\mathrm{U}(\text { fair })=\mathrm{m}^{\mathrm{c}} & +\mathrm{v}-\mathrm{p}^{\text {fair }}-\beta \cdot \max \left\{\mathrm{m}^{\mathrm{c}}+\mathrm{v}-\mathrm{p}^{\text {fair }}-\mathrm{m}^{\mathrm{t}} ; 0\right\} \\
& \left.\geq \mathrm{m}^{\mathrm{c}}+\mathrm{v}-\mathrm{p}^{\text {unfair }}-\beta \cdot \max \left\{\mathrm{m}^{\mathrm{c}}+\mathrm{v}-\mathrm{p}^{\text {unfair }}-\left(\mathrm{m}^{\mathrm{t}}-\mathrm{e}\right) ; 0\right\}=\mathrm{U} \text { (unfair }\right)
\end{aligned}
$$


With $\mathrm{p}^{\text {fair }} \leq \mathrm{v}$ and $\mathrm{p}^{\text {unfair }} \leq \mathrm{v}$, this simplifies to

$$
\Delta \mathrm{p}=\mathrm{p}^{\text {fair }}-\mathrm{p}^{\text {unfair }} \leq \frac{\beta \mathrm{e}}{1-\beta}
$$

Hence, a socially responsible consumer buys the fair product instead of the unfair product if $\Delta p$, the price premium for the fair product, does not exceed the r.h.s. of (1). The important observation is that a socially responsible consumer is willing to pay a higher price for the fair than for the unfair product even though the material value, $v$, to the consumer is identical for both types of products. The increasing curve in Figure Al illustrates the price premium the consumer is willing to pay as a function of $\beta$. The size of the externality in Figure $\mathrm{A}$ is set to $\mathrm{e}=60$ as in our experiment.

\section{A2. Price premium that a firm demands for offering the fair product}

Consider next a socially responsible firm that experiences a "disutility" equal to $\beta<1$ times the positive difference between its own payoff and that of the third party, in addition to the utility from its own monetary payoff. A socially responsible firm requires the following price premium in order to be willing to sell the fair instead of the unfair product.

$$
\begin{aligned}
\Pi(\text { fair })=\mathrm{m}^{\mathrm{f}} & +\mathrm{p}^{\text {fair }}-\mathrm{c}-\beta \cdot \max \left\{\mathrm{m}^{\mathrm{f}}+\mathrm{p}^{\text {fair }}-\mathrm{c}-\mathrm{m}^{\mathrm{t}} ; 0\right\} \\
& \left.\geq \mathrm{m}^{\mathrm{f}}+\mathrm{p}^{\text {unfair }}-\beta \cdot \max \left\{\mathrm{m}^{\mathrm{f}}+\mathrm{p}^{\text {unfair }}-\left(\mathrm{m}^{\mathrm{t}}-\mathrm{e}\right) ; 0\right\}=\Pi \text { (unfair }\right)
\end{aligned}
$$

With $\mathrm{p}^{\text {fair }} \geq \mathrm{c}$ and $\mathrm{p}^{\text {unfair }} \geq 0$, this simplifies to

$$
\Delta \mathrm{p}=\mathrm{p}^{\text {fair }}-\mathrm{p}^{\text {unfair }} \geq \mathrm{c}-\frac{\beta \mathrm{e}}{1-\beta}
$$

A socially responsible firm is thus willing to offer the fair product at a price premium that does not fully cover the higher cost, $c$, of production. Put differently, in order to be willing to offer the unfair product, a socially responsible firm demands a markup of at least $\beta \mathrm{e} /(1-\beta)$ on top of the cost of production of the unfair product (normalized to zero in our setting) as a compensation for imposing the externality on the third party. The decreasing curves in Figure A1, illustrate the required price premium for $c=10$ (solid line) and $c=40$ (dashed line), which correspond to the cost of production of the fair product type in the baseline and the high cost conditions, respectively. 
Figure A1. Price Premium as Functions of the Inequity Aversion Parameter $\beta$

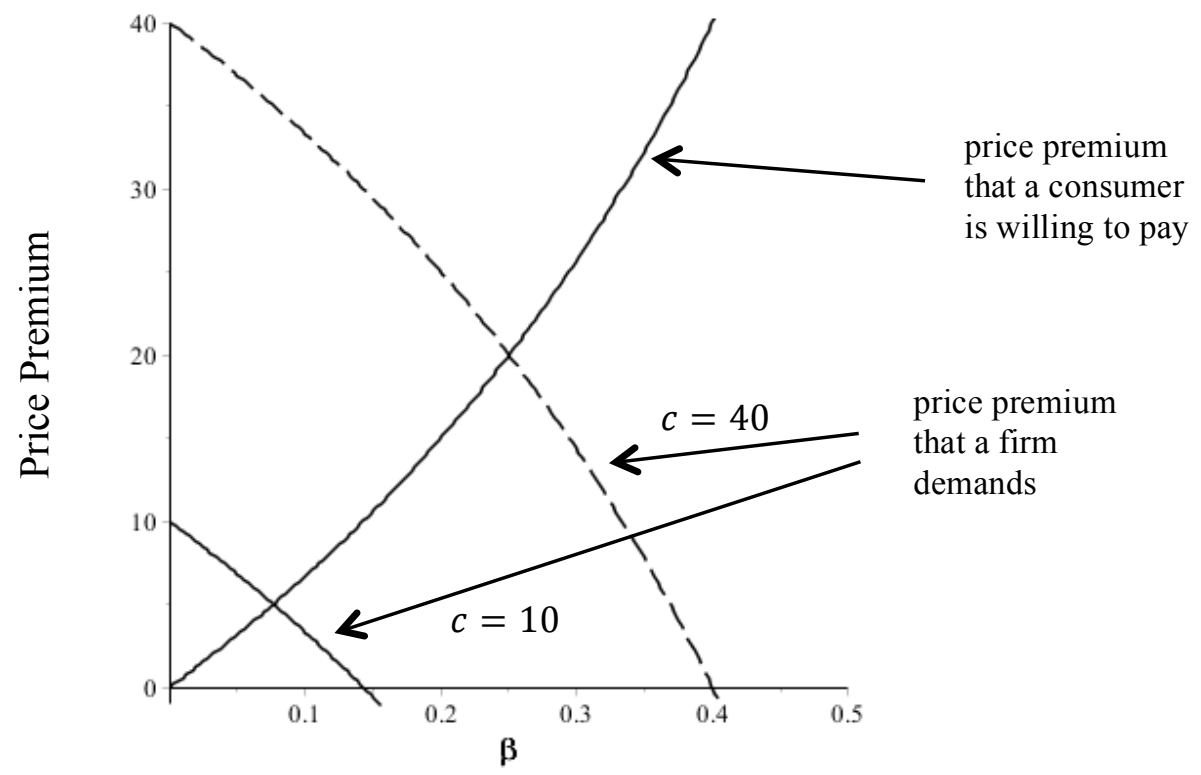

Notes: The figure shows the price premium $\Delta \mathrm{p}$ that a consumer is willing to pay for the fair product on top of the price of the unfair product (increasing line) and the price premium that a firm demands for offering the fair product instead of the unfair product (decreasing lines; solid for $c=10$, dashed for $c=40$ ) as a function of $\beta$. The externality is set to $e=60$.

\section{A3. Conditions under which trade of the fair product is feasible}

Assume, for simplicity, that both firm and consumer have the same degree $\beta$ of concern about the third party. It then follows from equations (1) and (2) that if $\beta \geq c /(c+2 e)$, a consumer's willingness to pay for the fair product is as least as high as a firm's required price premium. In such cases, there will always be a price premium such that trading the fair product becomes feasible. ${ }^{39}$ However, the higher the relative cost of production of the fair product, the higher the necessary level of $\beta$ such that trade of the fair product becomes feasible: with $c=10$ this level is $\beta=1 / 13$, and with $c=40$ it is $\beta=1 / 4$, given $e=60$. If $\beta=\mathrm{c} /(\mathrm{c}+2 \mathrm{e})$, the price premium is $c / 2$, i.e., firm and consumer each bear exactly half of the higher cost of production of the fair product. This corresponds to the intersection of the curves shown in Figure A1.

If $\beta \geq \mathrm{c} /(\mathrm{c}+\mathrm{e})$, which is $\beta \geq 1 / 7$ with $c=10$ and $\beta \geq 4 / 10$ with $c=40$, it is possible for either the firm or the consumer to bear the entire additional production cost, i.e. all

\footnotetext{
${ }^{39}$ In general, without assuming that consumer and firm have the same $\beta$, trade of the fair product becomes feasible if $\beta^{\mathrm{c}} \mathrm{e} /\left(1-\beta^{\mathrm{c}}\right) \geq \mathrm{c}-\beta^{\mathrm{f}} \mathrm{e} /\left(1-\beta^{\mathrm{f}}\right)$, where $\beta^{\mathrm{c}}$ and $\beta^{\mathrm{f}}$ denote the consumer's and firm's individual and potentially different concern for the third party.
} 
price premiums between 0 and $\mathrm{c}$ are possible. In Figure A1 this corresponds to the values of $\beta$ that are given by the intersection of the respective decreasing curve with the $\beta$-axis (firm's required price premium is zero) or where the increasing curve reaches the value of 10 or 40 , respectively (consumers are willing to pay for the entire additional cost of producing the fair product).

\section{A4. The market equilibrium with purely self-interested preferences}

Given that there are more firms than consumers in our experiment and that each firm and consumer can trade at most one product, the pure self-interest theory predicts that price competition among firms leads to prices equal to cost in equilibrium. That is, the price of the fair product will be $\mathrm{p}^{\text {fair }}=c$ and the price of the unfair product will be $\mathrm{p}^{\text {unfair }}=0$. Purely selfinterested consumers would, however, not buy the fair product at price $\mathrm{p}^{\text {fair }}=c$ but always the unfair product at price $\mathrm{p}^{\text {unfair }}=0$. Given that a firm's monetary profit equals zero for both types of product, purely self-interested firms are indifferent between offering a fair or an unfair product, and they also do not care whether they can sell or not (recall that the cost of production is incurred only if a product offer is sold). The pure self-interest model thus predicts that only the unfair product is traded at price $\mathrm{p}^{\mathrm{unfair}}=0$ in equilibrium.

\section{A5. Heterogeneous inequity-averse preferences}

To study a prediction for the competitive market with socially responsible behavior and for preference type heterogeneity, we use the distribution of preference types suggested by Fehr and Schmidt (1999) in Table III (p. 844). According to this distribution, 30 percent of subjects (i.e., of consumers and of firms) are purely self-interested with $\beta=0,30$ percent of subjects have $\beta=0.25$, and 40 percent have $\beta=0.6{ }^{40}$ In the following, we derive the market equilibria predicted under such preferences, for $c=10$ and $c=40$, respectively. Since we are interested in qualitative predictions, we ignore, for simplicity, the integer problem in our markets with 5 consumers and 6 firms.

\section{A5.1. The market equilibrium with $c=10$}

The predictions of the Fehr-Schmidt model in our baseline condition with $\mathrm{c}=10$ and $\mathrm{e}=60$ are given as follows (for both the Market Baseline and the High Firm Competition conditions):

\footnotetext{
${ }^{40}$ Note that $\beta<1$ implies that buying a fair product offer is always better than not buying at all.
} 
- The market share of the fair product is 70 percent.

- The fair product trades at $\mathrm{p}^{\text {fair }}=10$ and the unfair product trades at $\mathrm{p}^{\text {unfair }}=0$.

In particular, the following actions form the market equilibrium: The 30 percent of firms with $\beta=0$ each offer the unfair product at $\mathrm{p}^{\text {unfair }}=0$, and the 30 percent of consumers with $\beta=0$ each accept an unfair product offer. The 70 percent of firms with $\beta=0.25$ or $\beta=0.6$ each offer the fair product at $\mathrm{p}^{\text {fair }}=10$, and the 70 percent of consumers with $\beta=0.25$ or $\beta=0.6$ each accept a fair product offer. Since there are more firms than consumers (for each preference type), supply meets demand for both types of product, i.e. all consumers can buy their preferred product but some firms cannot sell their product offer.

To see that the above actions form an equilibrium, consider possible deviations by the market participants.

Consider first the consumers. Neither the selfish consumers with $\beta=0$ nor the socially responsible consumers with $\beta=0.25$ or $\beta=0.6$ have an incentive to deviate to not buying because at the given prices they realize payoffs from buying of, respectively, 50 and $(1-\beta) 40$. Moreover, none of the consumers has an incentive to deviate and buy the respective other product type. This follows from equation (1), showing that a consumer's willingness to pay for the fair product on top of the price of the unfair product is given by $\Delta p=60 \beta /(1-\beta)$. Purely self-interested consumers with $\beta=0$ thus strictly prefer buying the unfair product at the given prices. The 30 percent of consumers with $\beta=0.25$ are however willing to pay a price premium of $\Delta \mathrm{p}=20$ and thus strictly prefer buying the fair product at the given prices. The 40 percent of consumers with $\beta=0.6$ never buy the unfair product as they would even give money to the third party in order to equalize payoffs.

Would any of the firms deviate? Consider first purely self-interested firms. Irrespective of whether such a firm can sell its unfair product offer at price $\mathrm{p}^{\text {unfair }}=0$, it does not realize a positive profit on top of its endowment. Deviating and offering the fair product at $p^{\text {fair }}=10$ would not lead to positive profits, irrespective of whether the offer will be sold or not, because the price just covers the cost of production. Offering a product at a price lower or higher than $\mathrm{p}^{\text {fair }}=10$ or $\mathrm{p}^{\text {unfair }}=0$, respectively, would lead to zero profits at best. A firm realizes losses for lower prices because the price does not cover the cost and it would not be able to sell at higher prices due to price competition. 
Consider now socially responsible firms with $\beta=0.25$ or $\beta=0.6$. Irrespective of whether such a firm sells its fair product offer at $\mathrm{p}^{\text {fair }}=10$, it does not realize a positive profit on top of its endowment. Deviating and offering the unfair product at $\mathrm{p}^{\text {unfair }}=0$ would lead to a loss in case the offer is sold (and to zero profits otherwise). The reason is that equation (2) shows that such a firm requires a markup of $60 \beta /(1-\beta)$ on top of the cost of production of the unfair product as a compensation for the disutility created by the externality imposed on the third party. As with purely self-interested firms, there is no incentive to deviate and offer a product at a price

lower or higher than $\mathrm{p}^{\text {fair }}=10$ or $\mathrm{p}^{\text {unfair }}=0$, respectively, because this would lead to zero profits at best.

\section{A5.2. The market equilibrium with $\mathrm{c}=\mathbf{4 0}$}

The predictions of the Fehr-Schmidt model in our high production cost condition with $\mathrm{c}=40$ and $\mathrm{e}=60$ are given as follows:

- The market share of the fair product is 40 percent.

- $\quad$ The fair product trades at $\mathrm{p}^{\text {fair }}=40$ and the unfair product trades at $\mathrm{p}^{\text {unfair }}=20$.

In particular, the following actions form the market equilibrium: The 60 percent of firms with $\beta=0$ or $\beta=0.25$ each offer the unfair product at $p^{\text {unfair }}=20$, and the 60 percent of consumers with $\beta=0$ or $\beta=0.25$ each accept an unfair product offer. There are more firms than consumers so that supply meets demand. While all firms with $\beta=0$ can sell their product offer, some firms with $\beta=0.25$ cannot. The 40 percent of firms with $\beta=0.6$ each offer the fair product at $\mathrm{p}^{\text {fair }}=40$, and the 40 percent of consumers with $\beta=0.6$ each accept a fair product offer. Since there are more firms than consumers, supply meets the demand, but some firms with $\beta=0.6$ cannot sell their product offer.

To see that the above actions form an equilibrium, consider first possible deviations by the consumers. No consumer has an incentive to deviate to not buying because they all receive strictly positive payoffs from buying - though smaller ones than in case of $c=10$. Moreover, neither purely self-interested consumers with $\beta=0$ nor socially responsible consumers with $\beta=0.6$ would deviate to buying the respective other product type as they strictly prefer to buy the unfair or fair product, respectively. Consumers with $\beta=0.25$, however, who are willing to pay a price premium of $\Delta \mathrm{p}=20$, are now indifferent between buying the fair product at 
$\mathrm{p}^{\text {fair }}=40$ or the unfair product at $\mathrm{p}^{\text {unfair }}=20$. Hence, they do not have an incentive to deviate to buying the fair product.

Consider now the firms. All purely self-interested firms with $\beta=0$ sell their unfair product offer at $\mathrm{p}^{\text {unfair }}=20$. In our markets there are more firms than consumers but less than twice as many. Given the demand of 60 percent of the consumers, it is thus possible that each of the overall 30 percent of purely self-interested firms can sell their offer. These firms do not have an incentive to deviate to offering the fair product because they strictly prefer selling the unfair product at $\mathrm{p}^{\text {unfair }}=20$, where they make positive profits, over selling the fair product at $\mathrm{p}^{\text {fair }}=40$. Importantly, since all firms with $\beta=0$ can sell at $\mathrm{p}^{\text {unfair }}=20$, none of them has an incentive to bid prices down as this would only lower their profits. ${ }^{41}$ Asking for a lower price for the fair product will even lead to losses. Asking for higher prices for either product type leads to zero profits as the product offer could not be sold.

Consider now socially responsible firms with $\beta=0.25$. Irrespective of whether such a firm sells its unfair product offer at $\mathrm{p}^{\text {unfair }}=20$, it does not realize a positive payoff. The reason is that equation (2) reveals that the markup of 20 on top of the cost of production of the unfair product just compensates them for the loss of imposing the externality on the third party. Importantly, this is the reason why firms with $\beta=0.25$ that cannot sell at $p^{\text {unfair }}=20$ would not bid down prices and sell the unfair product at a price below 20. At any price $\mathrm{p}^{\text {unfair }}<20$ firms with $\beta=0.25$ would strictly prefer to not sell any product. Equation (2) also reveals that firms with $\beta=0.25$ are indifferent between selling the fair product at $\mathrm{p}^{\text {fair }}=40$ or the unfair product at $\mathrm{p}^{\text {unfair }}=20$, as they require a price premium of $\Delta \mathrm{p} \geq 20$ in order to sell the unfair product. Hence, they have no incentive to deviate and offer the fair product. Socially responsible firms with $\beta=0.6$ would never offer the unfair product; they just break even at $\mathrm{p}^{\text {fair }}=40$. Note, finally, that offering either product type at higher or lower prices would, at best, lead to zero profits for socially responsible firms, i.e., there is no incentive to ask for different prices.

\footnotetext{
${ }^{41}$ If there were more purely self-interested firms than demand for the unfair product at $\mathrm{p}^{\text {unfair }}=20$, such firms would bid prices down to cost, i.e. to $\mathrm{p}^{\text {unfair }}=0$. Consumers with $\beta=0.25$ would then strictly prefer buying the unfair product and firms with $\beta=0.25$ would strictly prefer offering the fair product at $p^{\text {fair }}=40$. The demand for the fair product from consumers with $\beta=0.6$ would then be served by firms with $\beta=0.25$ or $\beta=0.6$. Hence, the price of the unfair product would decline, but the market share of the product types would remain unchanged.
} 


\section{Appendix B: Additional Analyses, Tables, and Figures}

\section{B1. Consumers' Information Acquisition Decisions}

In this appendix we provide more detail on the consumers' information acquisition decisions. The frequencies of information acquisition, 73 and 42 percent when information acquisition is free and costly, respectively, are fairly stable across time. If we consider all 8 three-period blocks, the frequencies vary between 66 percent and 79 percent in the Free Limited Information condition and between 36 and 47 percent in the Costly Limited Information condition. Randomeffects probit regressions of information acquisition reveal no significant time trend in either condition.

Figure B1 shows the type of product purchased, conditional on consumers' information acquisition decisions. In both Limited Information conditions, consumers who do not acquire information typically purchase the product available with the lowest price and thus end up purchasing an unfair product, particularly after the first few periods. If we consider only cases in which a consumer's choice set includes both product types, then across both Limited Information conditions the lowest-priced product is an unfair product 94 percent of the time; in the second half of the experiment (Periods 13-24), this proportion rises to 99 percent.

Meanwhile, a large majority of consumers who pay for information purchase fair products (see the line labeled, "LI Costly - Info"). The fact that only 75 percent of buyers who paid for product information purchased fair products is driven both by limited product choices and by price sensitivity. For example, among those who acquired product information and saw both types of products, a higher proportion ( 81 percent) purchased fair products. Breaking down these cases by the price difference between the cheapest fair and unfair products available, we see that the frequency of fair product purchases decreases in the price difference-e.g., 97 purchase fair products when the price difference is 0 or 1,72 percent do so when it is between 2 and 5, 67 percent do so when it is 6 or greater, and the proportion is also 67 percent when it is 10 or more (in which case the consumer is paying the entire production cost of the fair product).

Not surprisingly, the proportion of consumers who acquire fair products following the acquisition of free information is lower-likely reflecting indifference between having and not having the information or curiosity without the intent to act on the obtained information. 
Figure B1. Product Purchases Conditional on Consumer Information Acquisition

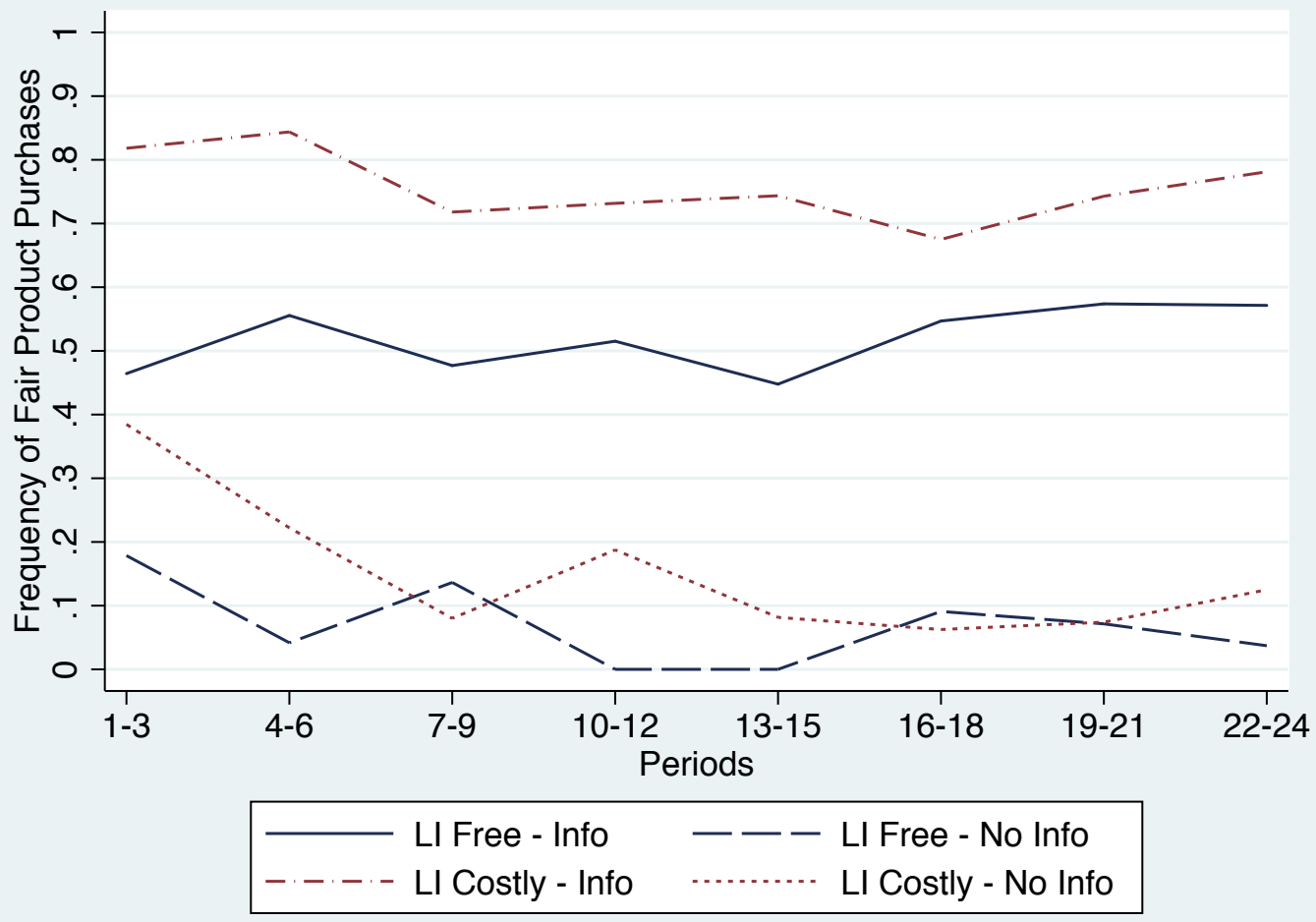




\section{B2. Additional Tables and Figures}

Table B1. Estimated Weights for Consumer Utility Model (Study 2)

\begin{tabular}{lcccc} 
& \multicolumn{2}{c}{ Market } & \multicolumn{2}{c}{$\begin{array}{c}\text { No Market } \\
\text { (using swapped choice sets only) }\end{array}$} \\
& Switzerland & China & Switzerland & China \\
\hline & $(1)$ & $(2)$ & $(3)$ & $(4)$ \\
\hline Consumer Earnings $(\theta)$ & $\begin{array}{c}0.272^{* * *} \\
(0.051)\end{array}$ & $\begin{array}{c}0.945^{* * *} \\
(0.125)\end{array}$ & $\begin{array}{c}0.246^{* * *} \\
(0.043)\end{array}$ & $\begin{array}{c}0.327^{* * *} \\
(0.040)\end{array}$ \\
Third Party Earnings $(\gamma)$ & $\begin{array}{c}0.020^{* * *} \\
(0.006)\end{array}$ & $\begin{array}{c}0.037^{* * *} \\
(0.006)\end{array}$ & $\begin{array}{c}0.043^{* * *} \\
(0.006)\end{array}$ & $\begin{array}{c}0.051^{* * *} \\
(0.007)\end{array}$ \\
\hline Observations & 4,827 & 4,821 & 4,823 & 4,823 \\
Cases & 960 & 960 & 960 & 960
\end{tabular}

Robust standard errors (clustered by subject) in parentheses

$* * * \mathrm{p}<0.01, * * \mathrm{p}<0.05, * \mathrm{p}<0.1$

The model includes period, gender and $\ln ($ age) as case-specific (intercept) terms (coefficients omitted). Ln(age) is positively related to making the default / no product choice in all models

Table B2. Estimated Weights for Consumer Utility Model (Market vs. No Market)

\begin{tabular}{|c|c|c|c|c|}
\hline & $\begin{array}{l}\text { Switzerland } \\
\text { (Study 1) }\end{array}$ & $\begin{array}{l}\text { Switzerland } \\
\text { (Study 2) }\end{array}$ & $\begin{array}{l}\text { Switzerland } \\
\text { (Pooled) }\end{array}$ & China \\
\hline & (1) & (2) & (3) & (4) \\
\hline Consumer Earnings $(\theta)$ & $\begin{array}{l}0.337^{* * *} \\
(0.040)\end{array}$ & $\begin{array}{l}0.248^{* * *} \\
(0.033)\end{array}$ & $\begin{array}{l}0.287^{* * *} \\
(0.025)\end{array}$ & $\begin{array}{l}0.511^{* * *} \\
(0.065)\end{array}$ \\
\hline Third Party Earnings $(\gamma)$ & $\begin{array}{l}0.029^{* * *} \\
(0.006)\end{array}$ & $\begin{array}{l}0.018^{* * *} \\
(0.006)\end{array}$ & $\begin{array}{l}0.023^{* * *} \\
(0.006)\end{array}$ & $\begin{array}{l}0.018^{* * *} \\
(0.006)\end{array}$ \\
\hline No Market X Third Party & $\begin{array}{c}0.012 \\
(0.009)\end{array}$ & $\begin{array}{l}0.019^{* *} \\
(0.008)\end{array}$ & $\begin{array}{l}0.016^{* * *} \\
(0.006)\end{array}$ & $\begin{array}{l}0.040^{* * *} \\
(0.008)\end{array}$ \\
\hline Observations & 8,410 & 9,654 & 18,064 & 9,640 \\
\hline Cases & 1,680 & 1,920 & 3,600 & 1,920 \\
\hline \multicolumn{5}{|c|}{$\begin{array}{l}\text { Robust standard errors (clustered by subject) in parentheses } \\
* * * \mathrm{p}<0.01, * * \mathrm{p}<0.05, * \mathrm{p}<0.1\end{array}$} \\
\hline
\end{tabular}


Figure B2: Prices by Product Type in the Limited Information Conditions

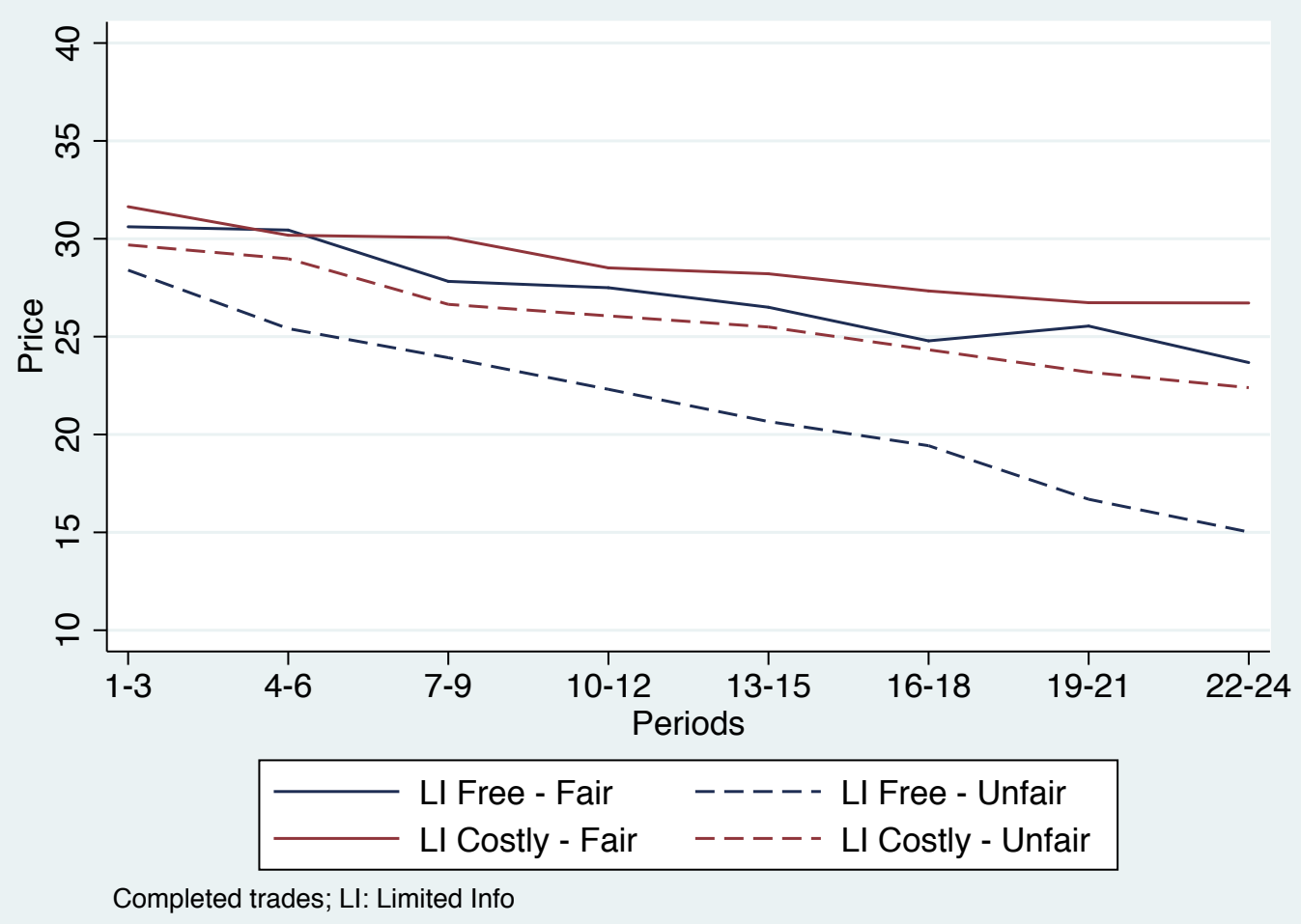

Figure B3: Prices by Product Type in the High Production Cost Condition

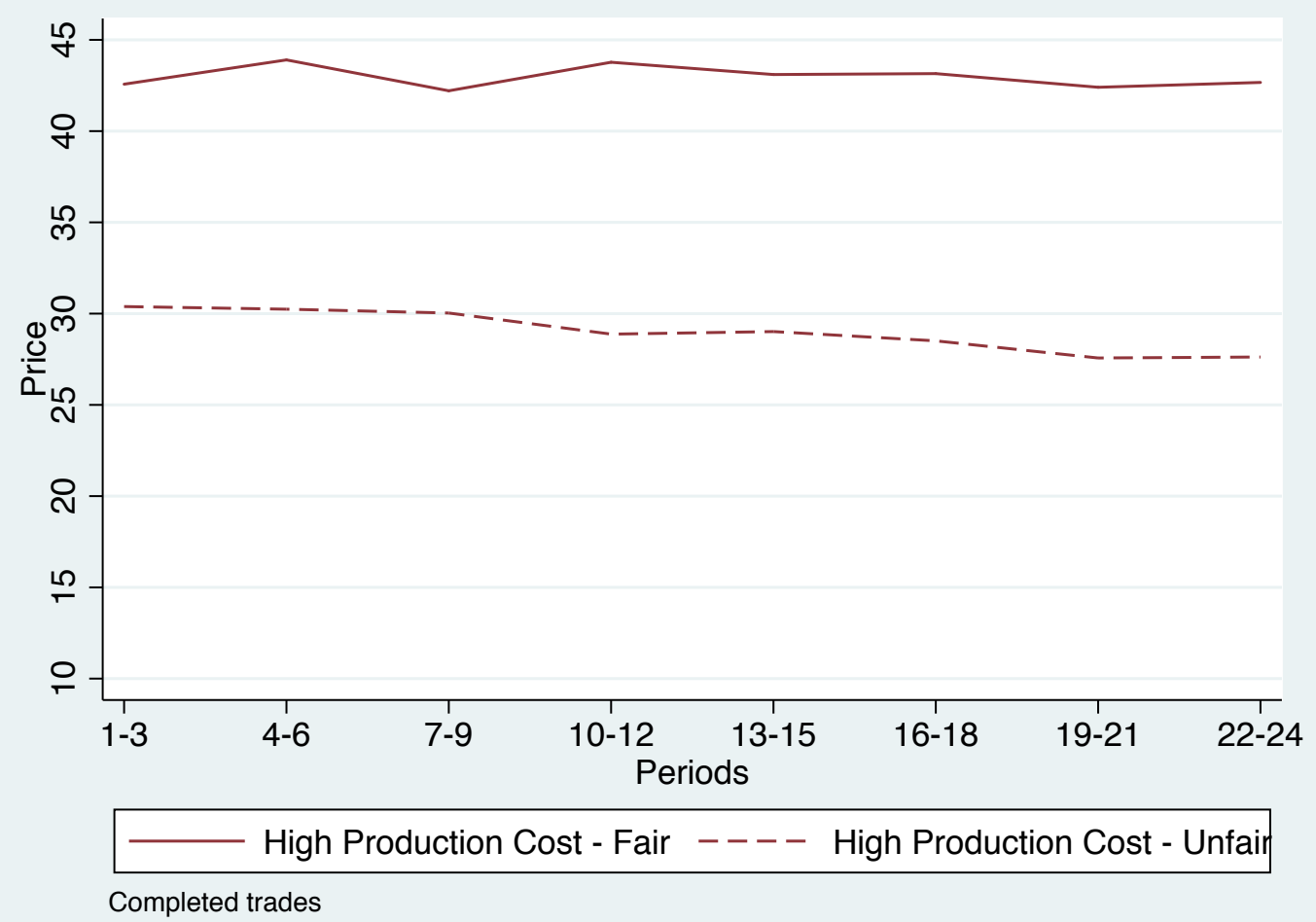


Figure B4: Distributions of Individual Behavior (High Firm Competition)
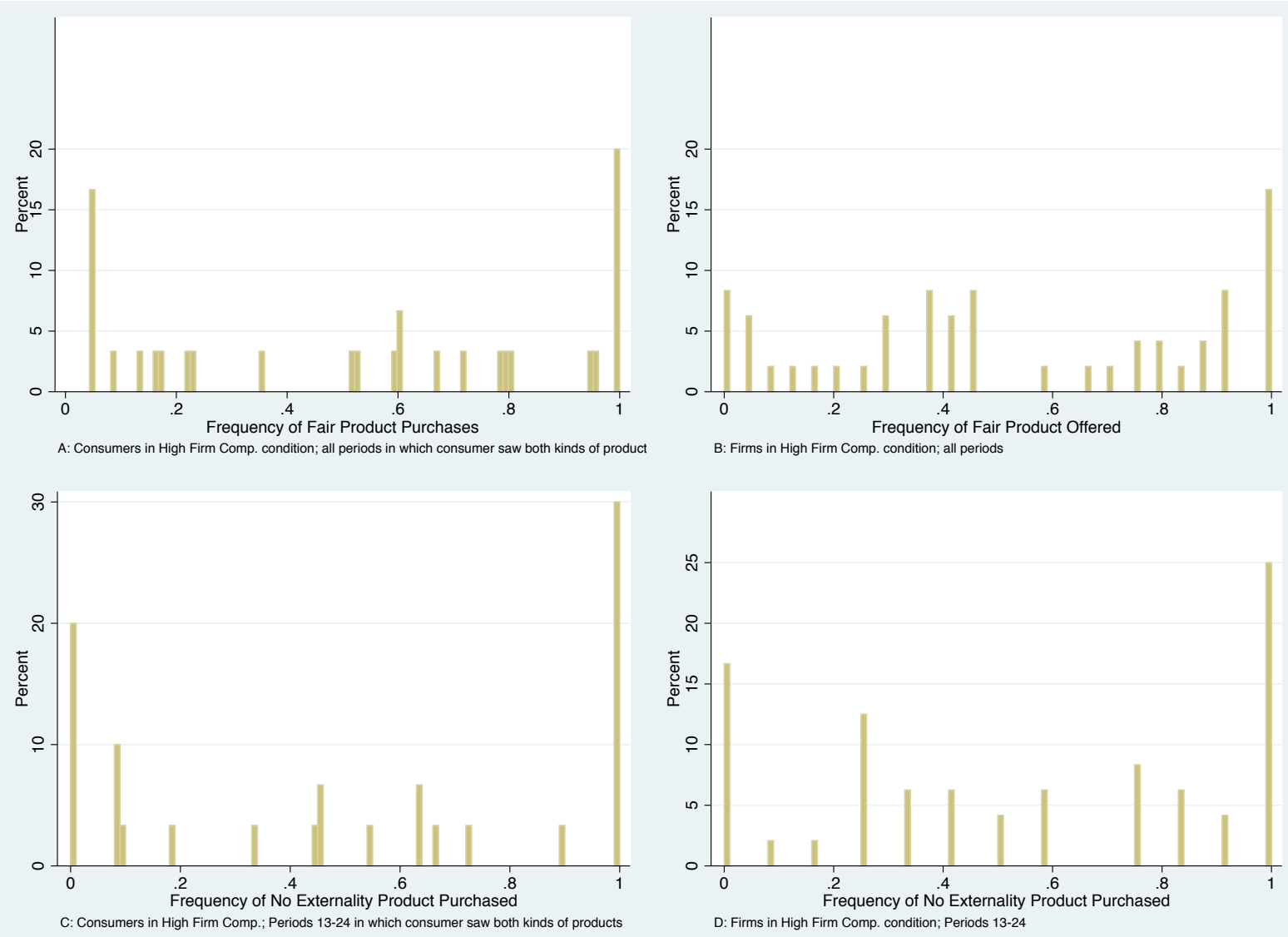
Figure B5: Distributions of Individual Behavior (Free Limited Information)
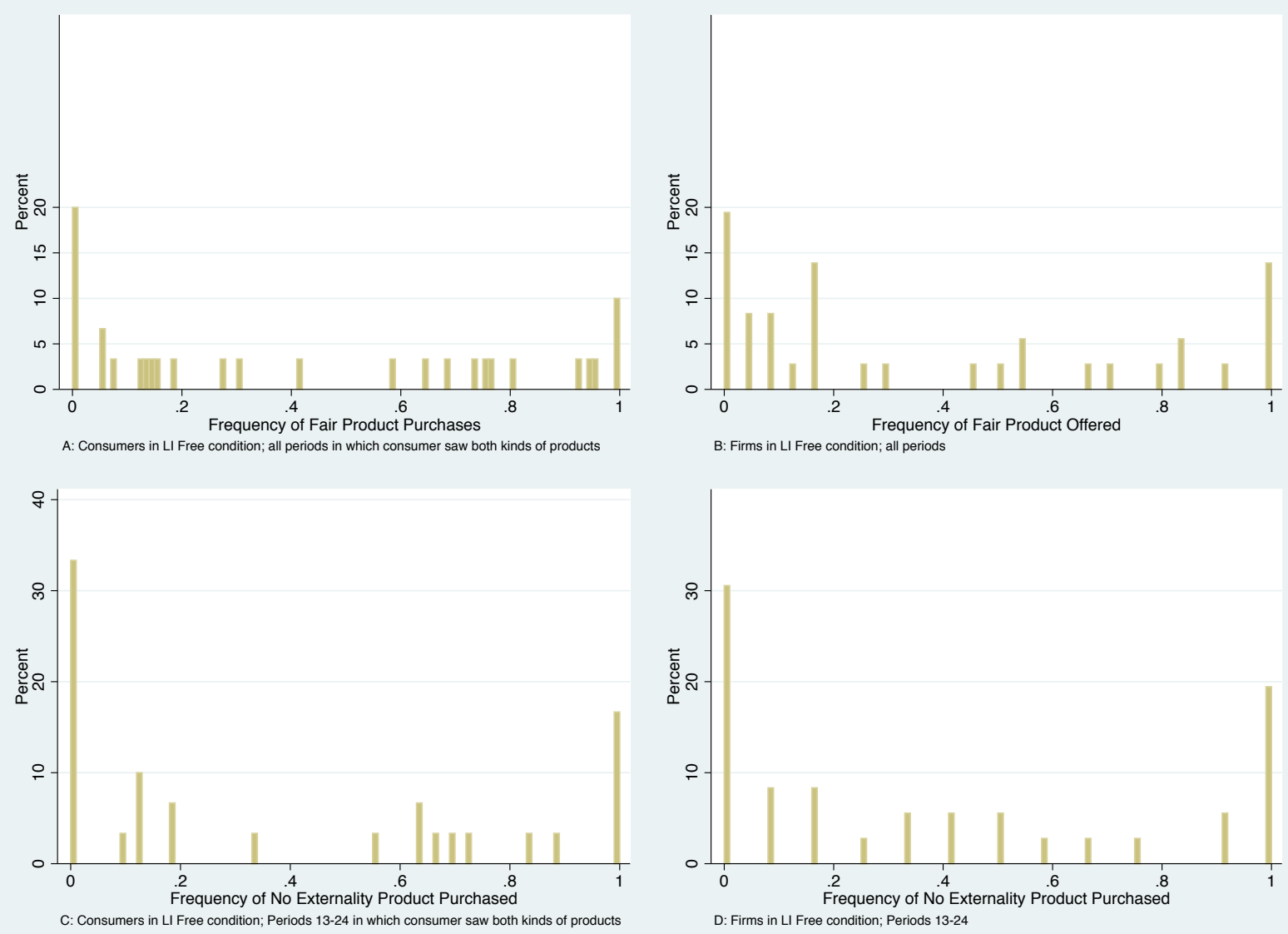
Figure B6: Distributions of Individual Behavior (Costly Limited Information)
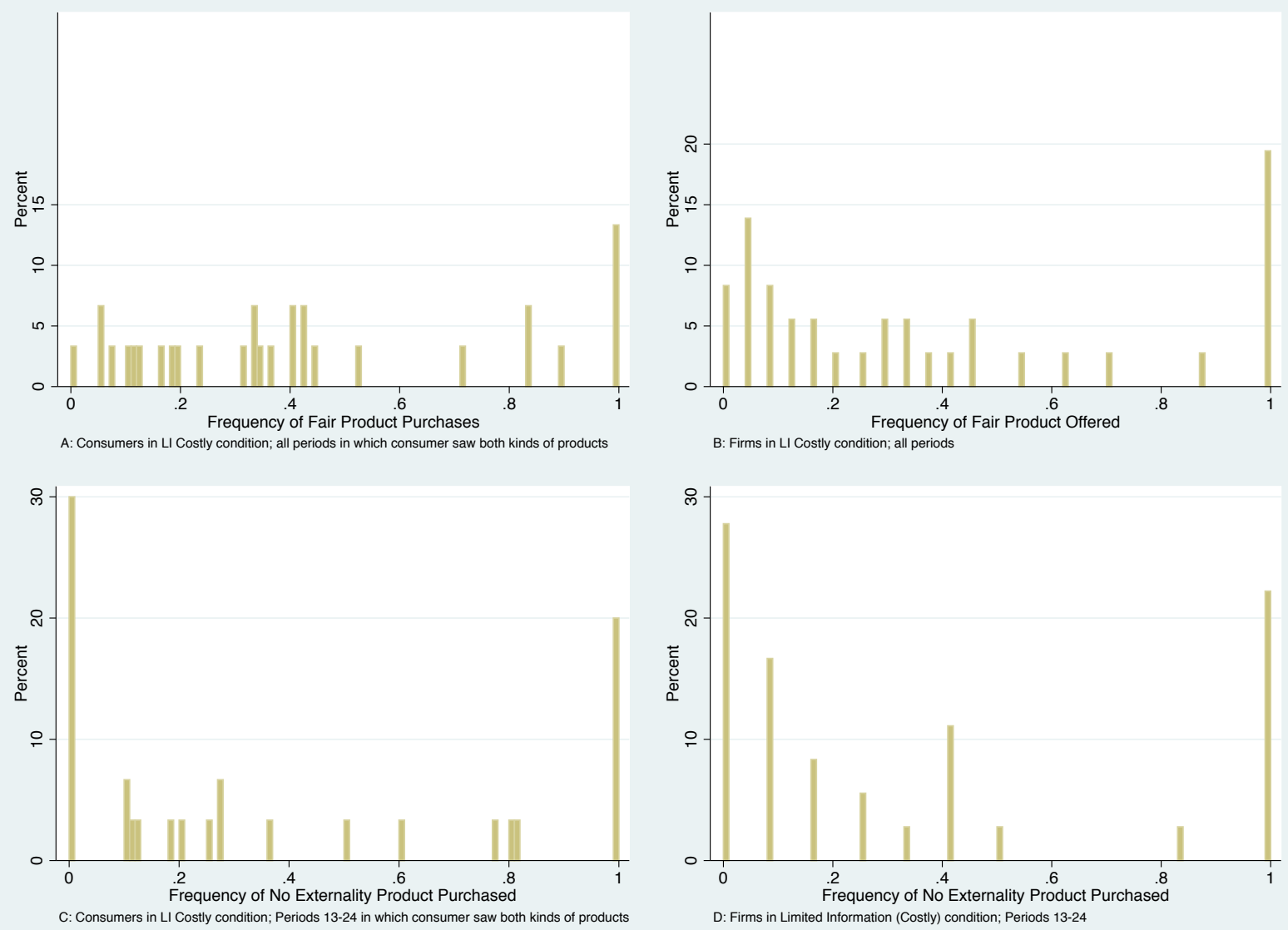
Figure B7: Distributions of Individual Behavior (High Production Cost)
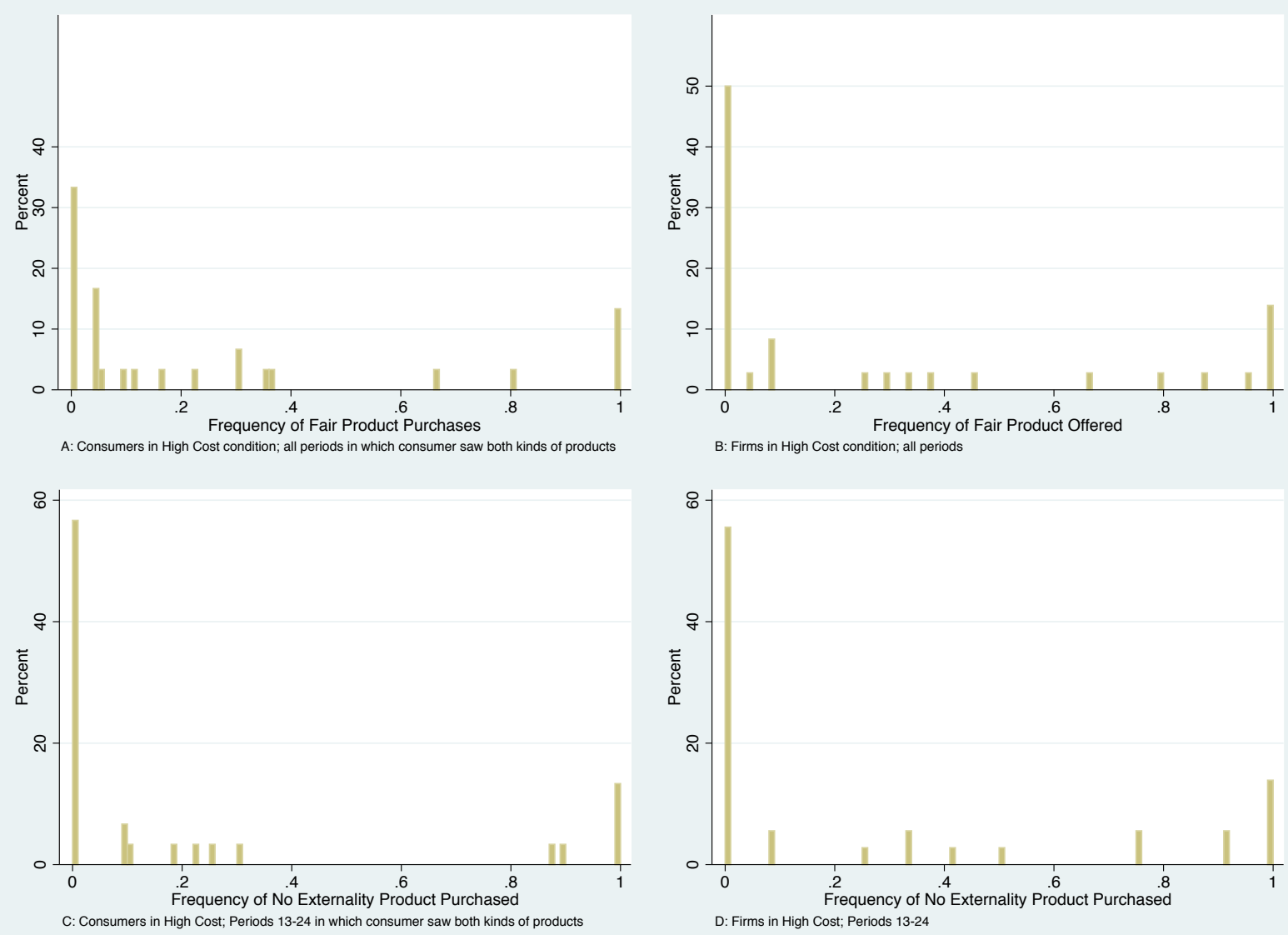
Figure B8. Fair Purchases / Choices in Market and No Market Conditions (excluding choices without a fair alternative)

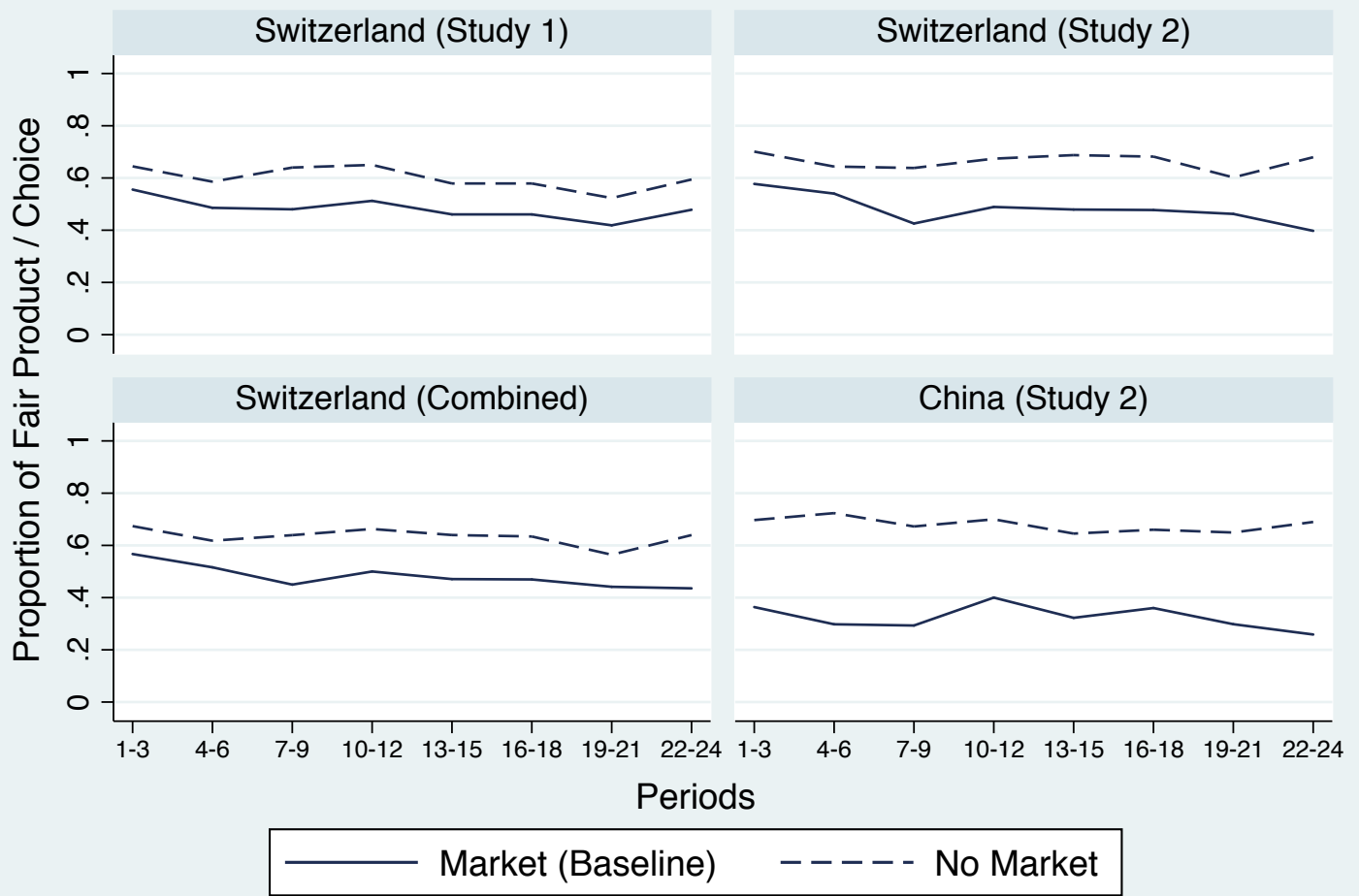

Graphs by location and sample; exclude choices with only one type of product / alternative 


\section{Appendix C: Experimental Instructions}

\section{A) Market Baseline}

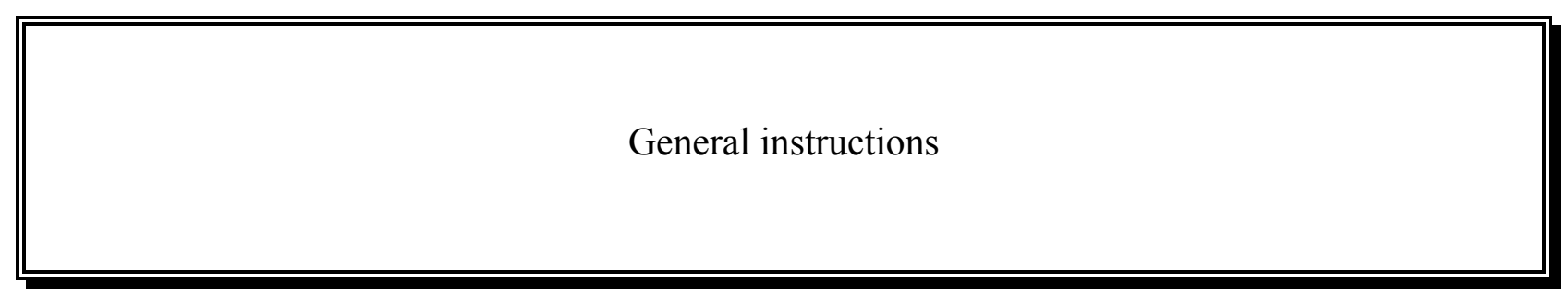

We are pleased to welcome you to this economic study.

If you read the following instructions carefully, you can - depending on your decisions and/or those of the other participants - earn money in addition to the $\mathbf{1 5}$ Swiss francs that you receive as an initial endowment for participating. It is thus very important that you read the instructions carefully. If you have any questions, please contact us.

Communication with the other participants is strictly forbidden during the study. Violation of this rule will lead to exclusion from the study and loss of all of the associated payments.

During the study, we will not speak of francs, but of points. Your entire income will thus first be calculated in points. The points you earn during the study will be converted to Swiss francs at the end of the study. The following conversion rate applies:

\section{0 points $=2.50$ Swiss francs.}

At the end of today's study, you will receive the number of points earned during the study plus the initial endowment of 15 Swiss francs for appearing in cash.

We will explain the exact procedure of the study on the next pages. For the sake of simplicity, we will always use male forms for participants; the instructions also obviously refer to female participants. 


\section{The study}

There are three types of participants in this study: participants A, B, and C. The participants in this study are divided into groups of 16 people. There are $\mathbf{6}$ participants A, 5 participants B, and 5 participants $\mathrm{C}$ in each group.

Participants $A$ are sellers, participants $B$ are buyers. Participants $C$ can neither sell nor buy, but they can incur losses due to the transactions between the participants $A$ and $B$.

The study last for 24 periods. In each period, each participant A makes exactly one sales offer for a product. Participant A thereby determines the type of product and the price for the product.

- There are two types of products:

\section{1. "Products with no effect on participant C" and}

\section{2. "Products with a loss for participant C".}

- Every value from 0 up to and including 50 can be selected as a price.

The production costs for participants A for a "product with no effect on participant C" amount to 10 points. Participant A bears no costs (0 points) for the production of a "product with a loss for participant C".

The value of a product for a participant B is always $\mathbf{5 0}$ points, regardless of what type of product it is.

The five participants B see the sales offers made by the six participants A (the price and the type of product) and can accept one offer each. The participants B can decide one after the other in a random order. Each participant B can only accept one offer. This means that a maximum of five of the six participants A can sell a product.

In each period, each of the five participants $B$ will be randomly assigned to one of the five participants C. If a participant B purchases a "product with a loss for participant C", the assigned participant $\mathrm{C}$ incurs a loss of $\mathbf{6 0}$ points. If a participant $\mathrm{B}$ purchases a "product with no effect on participant C" or no product at all, the assigned participant $\mathrm{C}$ incurs no loss.

You will see whether you are participant $A, B$, or $C$ on your screen at the beginning of the study. Your role as participant $\mathrm{A}, \mathrm{B}$, or $\mathrm{C}$ remains the same during the entire study. 
In each period, each participant $\mathrm{A}, \mathrm{B}$, and $\mathrm{C}$ first receives an endowment of 100 points. The payment in points of participant A (seller), participant B (buyer), and participant $\mathrm{C}$ in a period are thus determined as follows:

\section{Participant A's payment}

- If a participant B accepts his sales offer

\section{0 - costs of production + price of the product}

where the production cost amounting to 10 points are incurred only with a "product without effect on participant $C$ ". The production costs for a "product with a loss for participant $\mathrm{C}$ amount to 0 .

- If no participant B accepts his sales offer: 100

\section{Participant B's payment:}

- If participant B accepts a sales offer

$$
100+50 \text { - price of the product }
$$

- If participant B does not accept a sales offer: 100

\section{Participant C's payment:}

- If the randomly assigned participant B chooses a "Product with loss for participant C"

$$
100-60=40
$$

- If the randomly assigned participant B chooses a "Product without effect on participant C" or does not purchase a product: 100 


\section{Procedures on the computer:}

In each period, participants A enter their sales offers on the following screen:

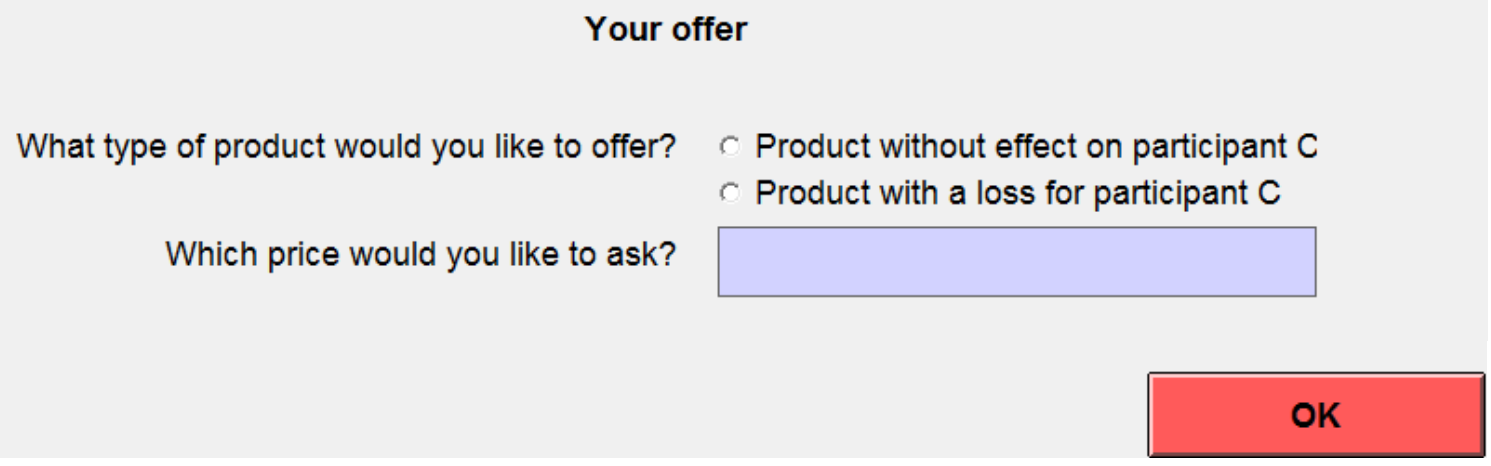

Participant A must indicate whether he wants to offer a "product without effect on participant C" or a "product with a loss for participant C." to do this, the corresponding type of product must be clicked on.

Furthermore, participant A must indicate the price he wants to request for the product. The corresponding number must be entered in the box. All integers from 0 up to and including 50 are possible.

Once a participant $\mathrm{A}$ has made his decisions, he must click on the OK button at the lower righthand side. The type of product and the price can be changed until the OK button is clicked.

Once all six participants A have made their sales offers, the participants A will see the sales offers (the price and the type of product) of all of the other participants $\mathrm{A}$ in a table. Here is an example:

\begin{tabular}{||c|c|c||}
\hline Price of the product & Type of the product & Order of acceptance \\
\hline $\begin{array}{c}\text { This is where the participants } A \\
\text { see the price of the product for } \\
\text { every sales offer }\end{array}$ & $\begin{array}{c}\text { This is where the participants } A \\
\text { see the type of product for } \\
\text { every sales offer }\end{array}$ & $\begin{array}{c}\text { accepted SECOND } \\
\text { accepted FIRT } \\
-\end{array}$
\end{tabular}

The participant's own sales offer is always marked in blue. Participants A can always see in the column on the right whether and in which order the participants B accept the offers.

Once all participants B have made their decisions, each participant A will learn of his own payment. If his offer is accepted, participant A will also learn participant B's payment and the payment of the corresponding participant $\mathrm{C}$. 
The participants B can see the sales offers on the screen below in each period:

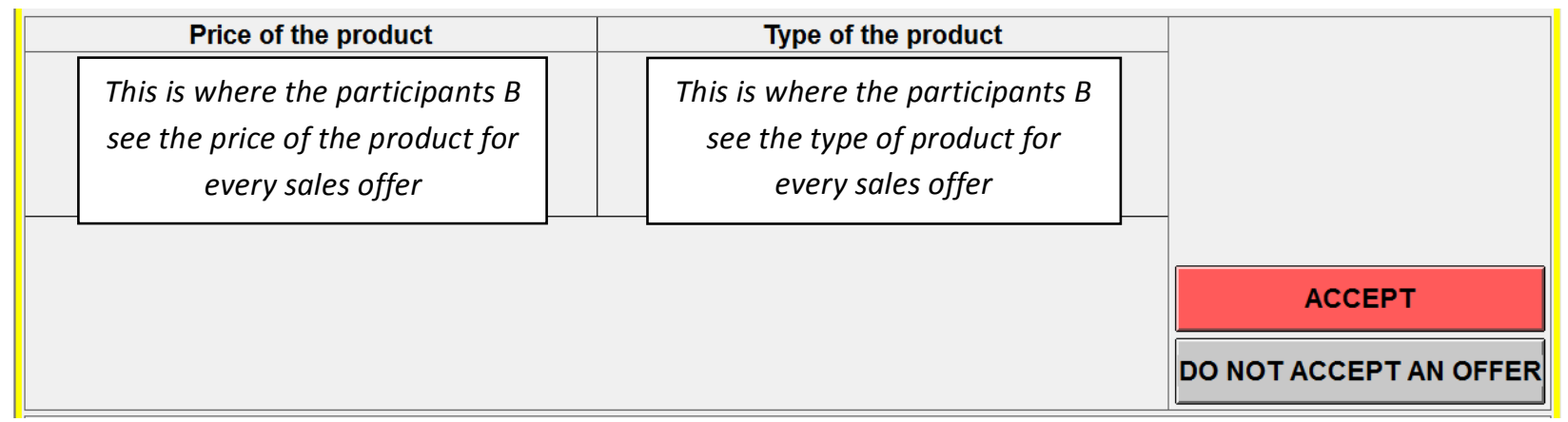

Participants B see the screen above in a random order and can accept an offer one after the other. Thus only one participant B sees the screen above at any one point in time. Only when the current participant B has made his decisions will the next participant B see the screen above, where he can then accept an offer.

The participant B who is first shown the screen can select from all offers. The participant B who is shown the screen second can only choose from the remaining offers, as each offer can only be accepted by one participant B.

If the five participants $\mathrm{B}$ have each accepted an offer, one offer will always remain that can no longer be accepted. The participant A who made this offer cannot conclude a sale in this period.

The order in which the five participants B decide on accepting the six offers will be randomly determined anew in each period.

The prices appear in the left column of the table, and the type of product appears in the right column. Each offer is always in a separate row. In order to accept an offer, the corresponding row must be clicked on with the mouse. The marked row will then appear with a blue background.

- In order to accept the offer marked in blue, you must click on the ACCEPT button.

The choice of offer can be changed until the ACCEPT button is clicked on.

If a participant B does not want to accept an offer, he must click on the DO NOT ACCEPT AN OFFER button. Even if a row had already been marked, all offers will be declined if the DO NOT ACCEPT AN OFFER is clicked on.

When all participants B have made their decisions, each participant B will learn of his own payment and that of his assigned participant $\mathrm{C}$. 
Participants $\mathbf{C}$ cannot make any decisions during this study. We ask the participants $\mathrm{C}$, however, to indicate in each period their expectations about the behaviors of participants $\mathrm{A}$ and B.

When all participants $\mathrm{A}$ and $\mathrm{B}$ have made their decisions, the participants $\mathrm{C}$ will learn of their own earnings, which are entirely dependent on the decisions of participants A and B.

After all participants have been informed about their payments in a period, the next period will begin.

Your earnings in this study are the payment out of one randomly selected period.

Because you do not know which period the computer will randomly select, you must consider your decisions in each of the 24 periods very carefully.

At the end of the study, the corresponding point amount will be converted to Swiss francs and paid in cash to you together with the initial endowment.

Do you have any further questions? If yes, please raise your hand. We will come to you at your workplace. Otherwise, we ask you to answer the control questions on the next pages.

\section{Control questions}

1. Assume that participant A offers a "product without effect on participant C" at the price of 40 and participant $B$ accepts the offer.

How high are the payments to participants A and B and the corresponding participant $\mathrm{C}$ ?

2. Assume that participant A offers a "product with a loss for participant C" at the price of 40 and participant $\mathrm{B}$ accepts the offer.

How high are the payments to participants A and B and the corresponding participant $\mathrm{C}$ ?

3. Assume that participant A offers a "product without effect on participant C" at the price of 15 and participant $B$ accepts the offer.

How high are the payments to participants A and B and the corresponding participant C?

4. Assume that participant $A$ offers a "product with a loss for participant $C$ " at the price of 15 and no participant $B$ accepts the offer.

How high is the payment for participant A? How high is the payment for a participant B who does not accept an offer? How high is the payment for the corresponding participant C?

Please raise your hand when you have completed the control questions. We will then come to you at your workplace. 


\section{B) No Market Condition}

[General instructions as in Market Baseline]

\section{The study}

There are three types of participants in this study: participants A, B, and C. The participants in this study are divided into groups of 3 people. There is one participant $\mathrm{A}$, one participant $\mathrm{B}$, and one participant $\mathrm{C}$ in each group.

The study last for 24 periods. In each period, one participant A, one participant $\mathrm{B}$, and one participant $\mathrm{C}$ are randomly assigned to one another.

In each period, the participants $\mathrm{A}, \mathrm{B}$, and $\mathrm{C}$ first receive an endowment of 100 points.

The Participant $B$ in a group can select a different distribution of points. In case of a new distribution, the sum of the payments that participants $\mathrm{A}$ and $\mathrm{B}$ receive is 40 or 50 points greater than the initial endowment of 100 points each.

There are two types of distributions:

\section{3. "Distribution with no effect on participant $C$ " and}

\section{4. "Distribution with a loss for participant C".}

If a participant B selects a "distribution with a loss for participant $C$," the assigned participant $\mathrm{C}$ incurs a loss of 60 points. If a participant B selects a "distribution with no effect on participant $\mathrm{C}$ " or does not opt for a new distribution, the assigned participant $\mathrm{C}$ will not incur any loss.

You will see whether you are participant $A, B$, or $C$ on your screen at the beginning of the study. Your role as participant $\mathrm{A}, \mathrm{B}$, or $\mathrm{C}$ remains the same during the entire study. 
In each period, each participant $\mathrm{A}, \mathrm{B}$, and $\mathrm{C}$ first receives an endowment of 100 points. The payment in points of participant $\mathrm{A}, \mathrm{B}$, and $\mathrm{C}$ in a period depend on the participant $\mathrm{B}$ 's decisions and are determined as follows:

\section{Participant A's payment}

- If the randomly assigned participant B selects a new distribution

\section{Payment in the new distribution}

- If the participant B does not select a new distribution: 100

\section{Participant B's payment:}

- If he selects a new distribution

\section{Payment in the new distribution}

- If he does not select a new distribution: 100

\section{Participant C's payment:}

- If the randomly assigned participant B chooses a "Distribution with loss for participant C"

$$
100-60=40
$$

- If the randomly assigned participant B chooses a "Distribution without effect on participant C" or does not select a new distribution: 100

In case of a "distribution without effect on Participant C," the sum of the payments for participant $\mathrm{A}$ and participant $\mathrm{B}$ is 40 points higher than if no new distribution is chosen, for example 125 points for participant $A$ and 115 points for participant B (and 100 points for participant C).

In case of a "distribution with a loss for Participant C," the sum of the payments for participant $\mathrm{A}$ and participant $\mathrm{B}$ is 50 points higher than if no new distribution is chosen, for example 120 points for participant $A$ and 130 points for participant $B$ (and $100-60=40$ points for participant C). 


\section{Procedures on the computer:}

In each period, participants $\mathbf{B}$ can select from possible new distributions on the following screen:

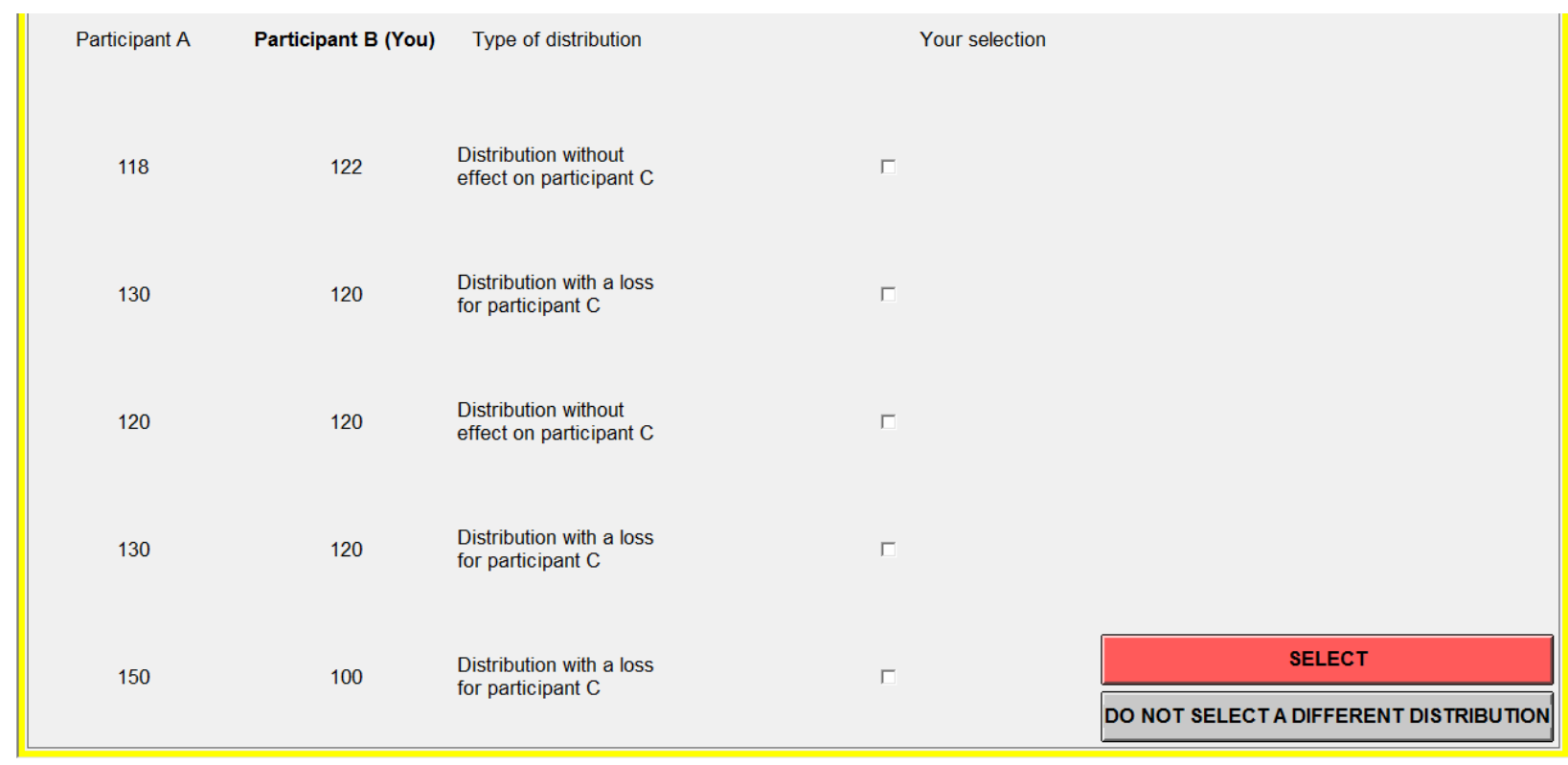

Participants B can choose from two to six different distributions in each period. In this case, for example, participant B can choose between five new, different distributions.

The left column of the table shows the possible payments for participant $\mathrm{A}$, the middle column shows the possible payments for participant $\mathrm{B}$, and the type of distribution is shown in the right column. Each new distribution always appears in a separate row. In order to select a new distribution, the box at the far right must be clicked on with the mouse.

- The SELECT button must be clicked on in order to select the chosen distribution.

The type of distribution can be changed until the SELECT button is clicked.

If a participant B does not want to select a new distribution, he must press the DO NOT SELECT A DIFFERENT DISTRIBUTION button. Even if new distribution had already been marked, no new distribution will be selected if the DO NOT SELECT A DIFFERENT DISTRIBUTION button is chosen.

When all participants $\mathrm{B}$ have made their decisions, the assigned participants $\mathrm{A}$ and $\mathrm{C}$ will be informed of the decision. 
Participants $\mathbf{A}$ and $\mathbf{C}$ cannot make any decisions during this study. We ask the participants $\mathrm{A}$ and $\mathrm{C}$, however, to indicate their expectations about the participant B's behavior in each period.

After all participants have been informed about their payments in a period, the next period will begin.

Your earnings in this study are the payment out of one randomly selected period.

Because you do not know which period the computer will randomly select, you must consider your decisions - if you are a participant $B$ - in each of the 24 periods very carefully.

At the end of the study, the corresponding point amount will be converted to Swiss francs and paid in cash to you together with the initial endowment.

Do you have any further questions? If yes, please raise your hand. We will come to you at your workplace. Otherwise, we ask you to answer the control questions on the next pages.

\section{Control questions}

1. Assume that participant $B$ chooses a new distribution and this is a "distribution without effect on participant C."

How high are the payments to the participants $\mathrm{A}, \mathrm{B}$, and $\mathrm{C}$ randomly assigned to each other in this period?

2. Assume that participant B chooses a new distribution and this is a "distribution with a loss for participant C."

How high are the payments to the participants A, B, and C randomly assigned to each other in this period?

3. Assume that participant $B$ chooses no new distribution.

How high are the payments to the participants A, B, and C randomly assigned to each other in this period?

Please raise your hand when you have completed the control questions. We will then come to you at your workplace. 